\title{
ON THE STATE
}

\section{OF THE \\ OPTIC NERVES AND RETIN开}

AS SEEN IN THE INSANE.

BY

T. CLIFFORD ALLBUTT, M.A., M.B. Cintab., F.L.S., \&C., PHYSICIAN TO THE LEEDS GENERAL IN FIRMARY, ETC.

Received Dec. 4th, 1867.-Bead Feb. 25th, 1868.

Ir is not my intention to delay the Medical and Chirurgical Society with any remarks beyond the matter in hand. I have made a series of observations upon the optic nerves and retinæ as seen in the insane, and I wish to confine myself simply to the record of my observations, and to such conclusions as these may seem to justify.

In some instances I find an abnormal state. of the nerves, in others a normal state. The cases in the former category may, perhaps, have more interest for the Society; but I may be allowed to say that the absence of morbid change in any one instance is as much to the point as is its presence in another. I submit that the records of negative are as valuable as the records of positive instances, the presence of a healthy optic nerve in one case of insanity being a fact as positive as the discovery of a failing nerve in another case.

vol. $\mathbf{L I}$. 
I think my records show, to some extent, in what kinds of brain disease, accompanied by insanity, we may expect to find optic changes, and in what kinds we may not expect them. The subject which I have ventured to take in hand is, however, one of extreme complexity, and I would be understood as speaking throughout with great hesitation.

My experience of changing optic nerves and retinæ is, indeed, now somewhat considerable, and many of my observations were repeated twice and even three times. I believe, therefore, that my notes may be received as trustworthy. My conclusions, on the contrary, must be both given and received with great hesitation. I shall be satisfied if my cases, which, comparatively speaking, are few, and my conclusions, which must, therefore, be very fallible, may be taken as stepping-stones to a better knowledge.

The Society will readily understand how an observer, who, like myself, had given some attention to cerebro-spinal diseases, was led on to inquire into the phenomena of insanity.

Even with the present more positive methods of dealing with disease, we scarcely realise sufficiently that a hospital for lunatics is, speaking generally, a museum of cerebral diseases.

Functional or organic disorder of the hemispheres depends upon many kinds and many degrees of change; it may depend upon primary disease of the hemispheres themselves, or upon interference with them by means of disease in other near or more distant parts.

It may, therefore, be objected to me that I have busied myself with an artificial family of disorders, composed of cases so heterogeneous as to forbid any discussion of them in common.

It may be said that I ought to have taken a series of cases classified, not by accidental disorder of a particular function, but by the pathological characters or the original positions of morbid changes.

I might reply by several answers. I would say, however, not by way of answer, but by way of explanation 
of my efforts in this direction, that I first examined the eyes of general paralytics for the chance of finding in the retina some of those changes of or about the bloodvessels, which several observers have described in the brain in persons who have died of that disease.

In this I was disappointed, but I was thus led to the discovery of a certain condition of the optic nerve in general paralysis which I shall describe presently. Having in this way begun my researches, I determined to continue them, because the tendency of researches of this kind is to remove the study of mental diseases from the metaphysical methods, and to place it upon a positive basis. I will only now say farther, that I hoped and still hope to find in the indications of the ophthalmoscope some test by which the alienist physician may sift the unwieldy mass of diseases with which he has to deal, and may approach a more certain knowledge of the various pathological conditions of his patients. I hope, for instance, that in dealing with mania the physician may be helped by the ophthalmoscope to decide, in doubtful cases, whether he has to deal with a mania depending upon organic or only upon functional changes, as the phrase is. It seems farther possible that the state of the vascular parts of the eye may indicate to some extent the state of the cerebral circulation in mania.

I shall not spend the time of the Society by entering upon any special questions concerning the nature or origin of mental disorder, nor even concerning its connection with various well-known pathological changes. I shall, for convenience, use the commonest classification, and, perhaps, the most useful, viz. general paralysis, idiocy, dementia, mania, monomania, and melancholia. I shall make a separate class of cases of insanity depending upon or connected with epilepsy. Such a classification is, I know, logically indefensible, but it will serve our purpose sufficiently well.

My observations have been made partly in the West Riding Lunatic Asylum, at Wakefield, with the help of Dr. Crichton Browne, whose diagnosis of each case I place in my schedules; and partly in the North and East Riding Asylum, at Clifton, 
near York, with the help of Dr. Christie, who selected and named for me a number of well-marked cases. I cannot sufficiently thank these gentlemen for their courtesy and pains. Upon Dr. Browne's time and patience I made large and repeated demands, to which he most generously responded.

The examinations were made at various dates during the second half of the year 1867 .

The examination of the eyes of lunatics is a very tedious and often a very trying task. My natural anxiety to note down no observation of a doubtful character, while, at the same time, to observe was so difficult, would have been too heavy a strain upon my attention had not Dr. Browne and Dr. Christie so materially lightened my labour by their interest in my work and by their hearty aid.

I shall draw the attention of the Society, in the first place, to my cases of general paralysis.

It is in this form of insanity that $I$ have the most definite results to communicate. 
AS SEEN IN TH́E INSANE.

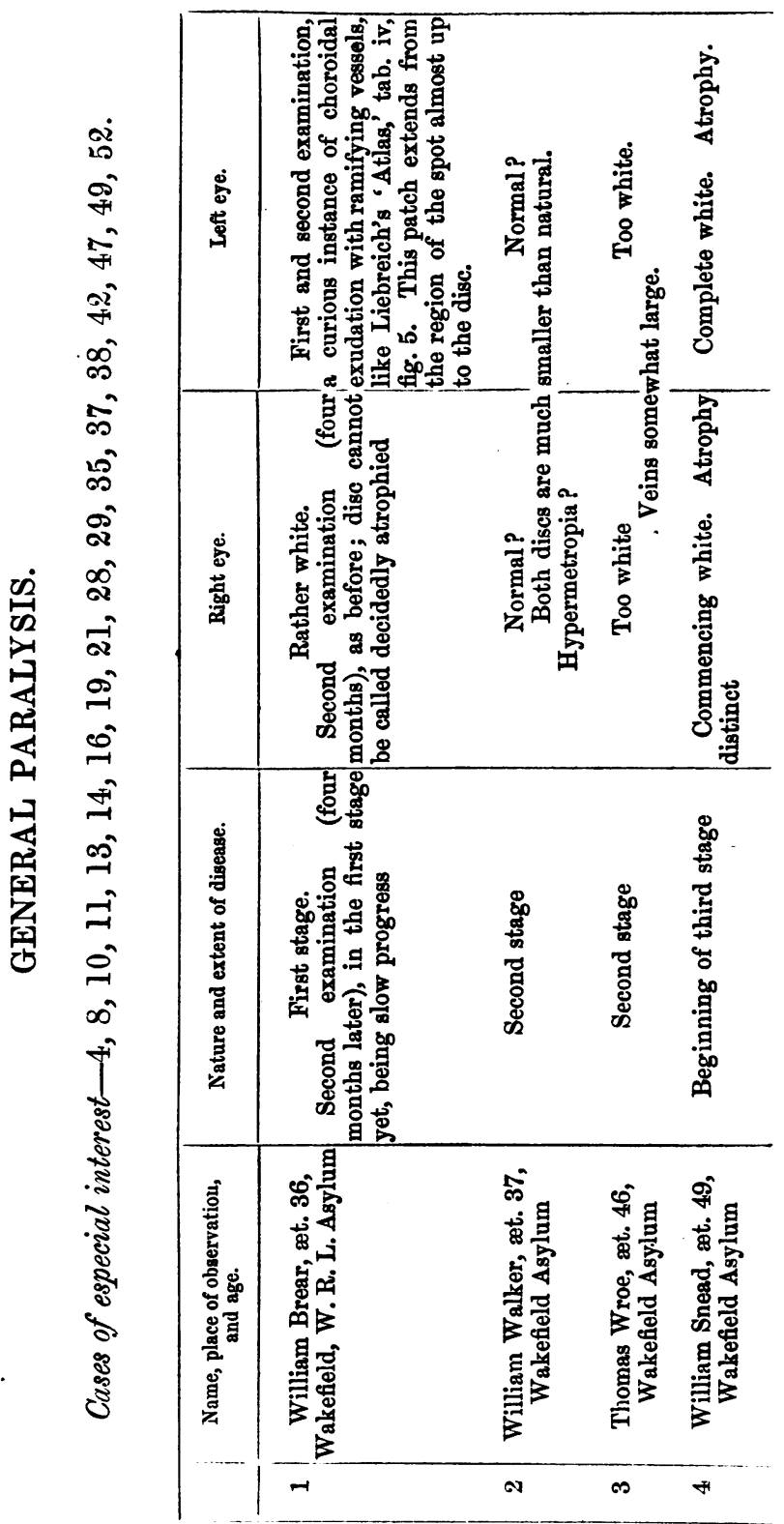




\begin{tabular}{|c|c|c|c|c|c|}
\hline $\begin{array}{l}\text { 灾 } \\
\text { 岕 }\end{array}$ & 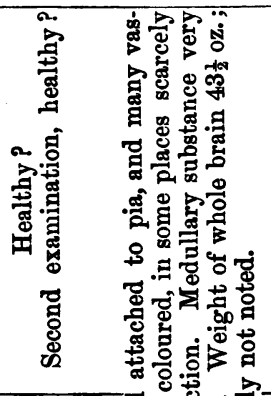 & 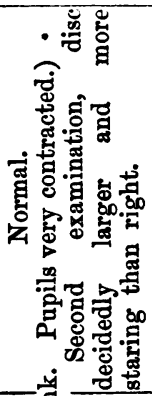 & 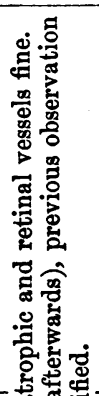 & 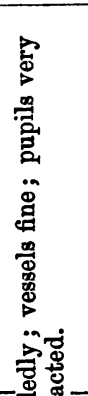 & 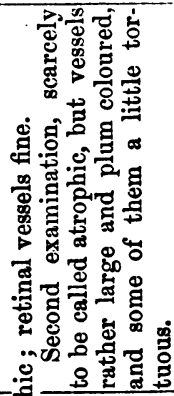 \\
\hline 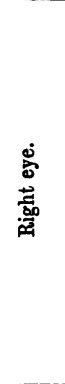 & 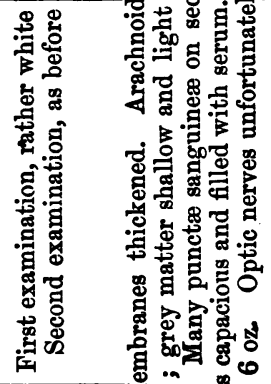 & 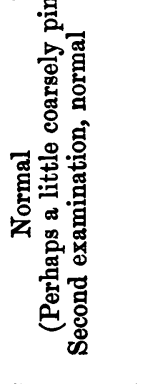 & 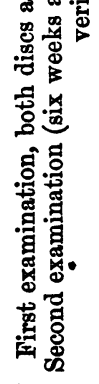 & 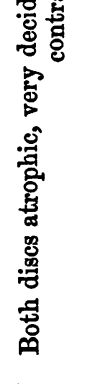 & 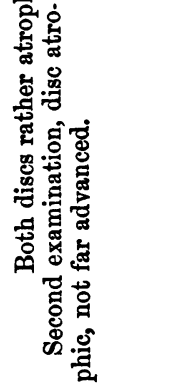 \\
\hline 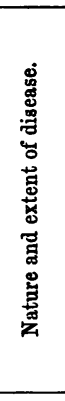 & 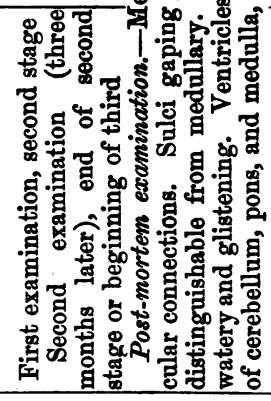 & 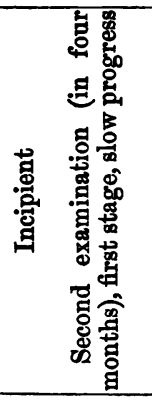 & 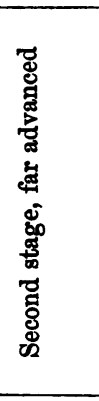 & 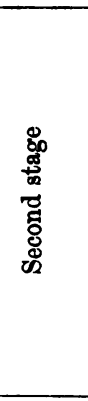 & 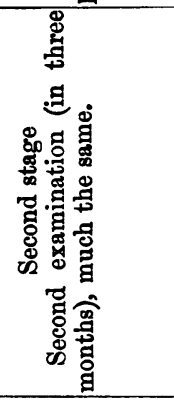 \\
\hline \multirow[t]{2}{*}{ 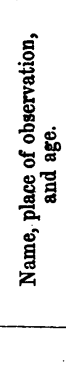 } & 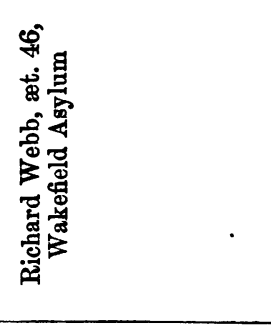 & 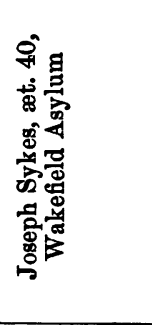 & 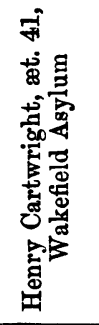 & 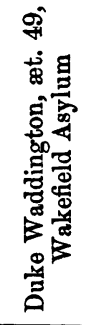 & 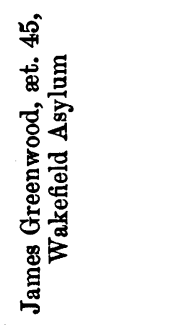 \\
\hline & مص & 0 & $N$ & $\infty$ & $\sigma$ \\
\hline
\end{tabular}


AS SEEN IN THE INSANE.

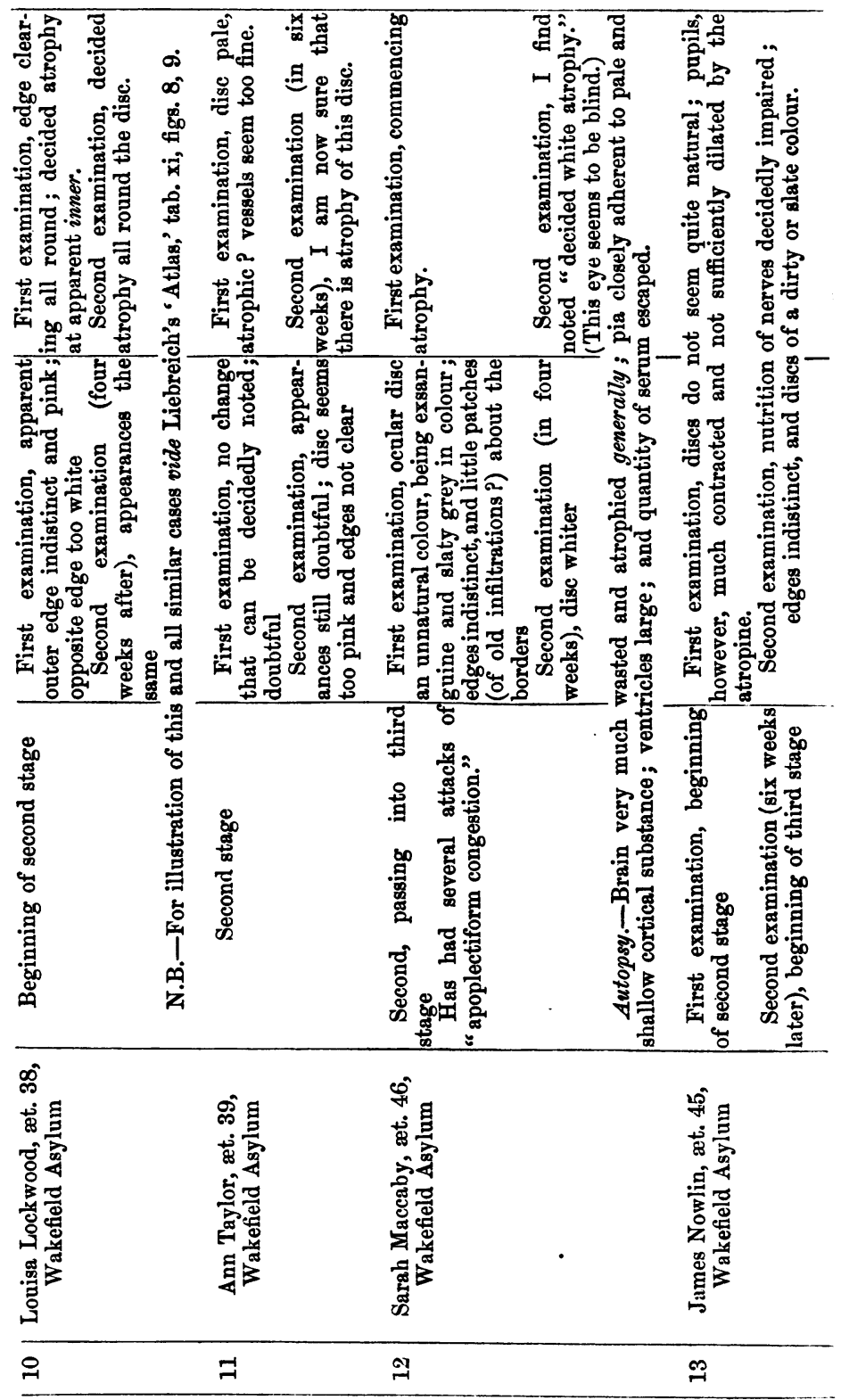




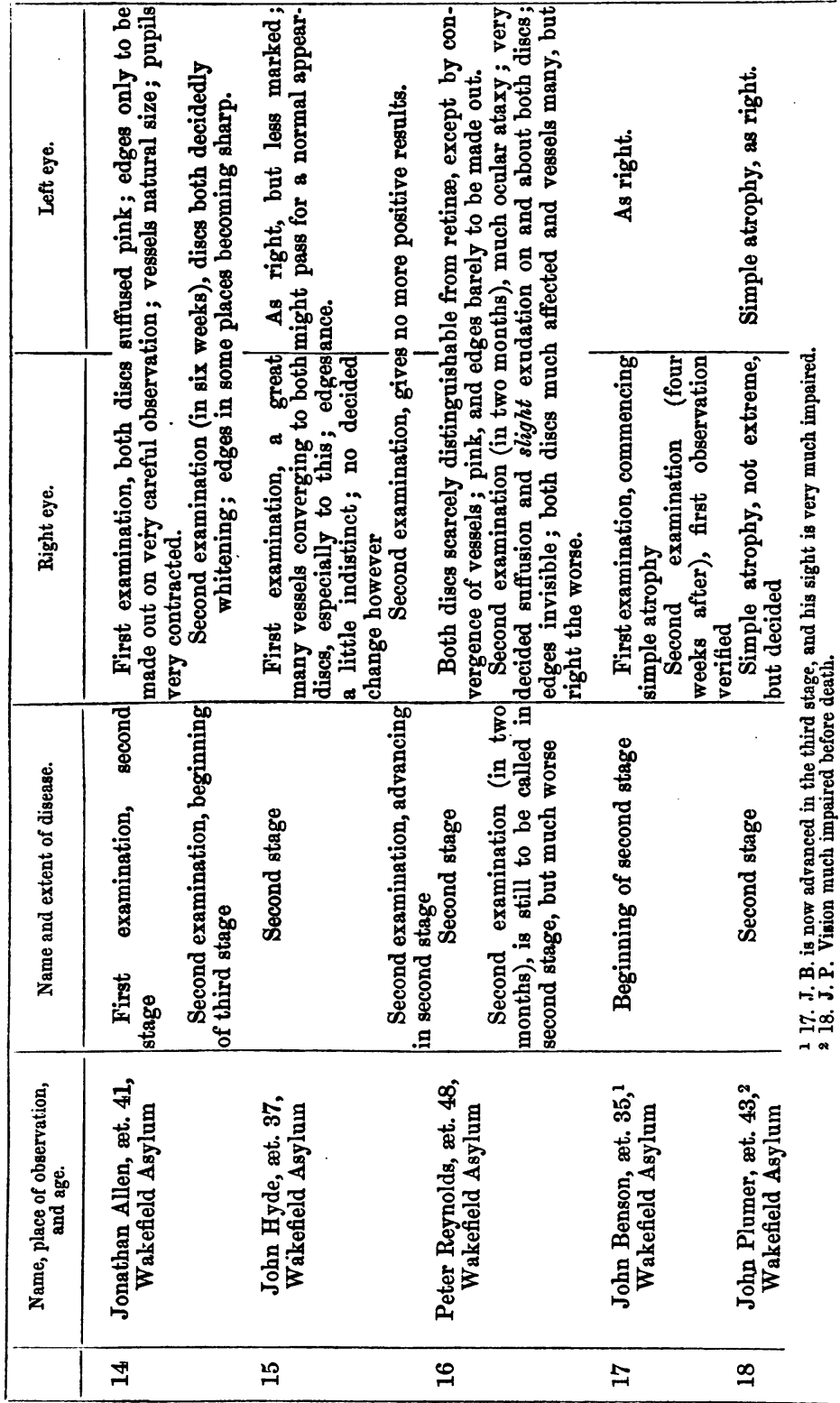




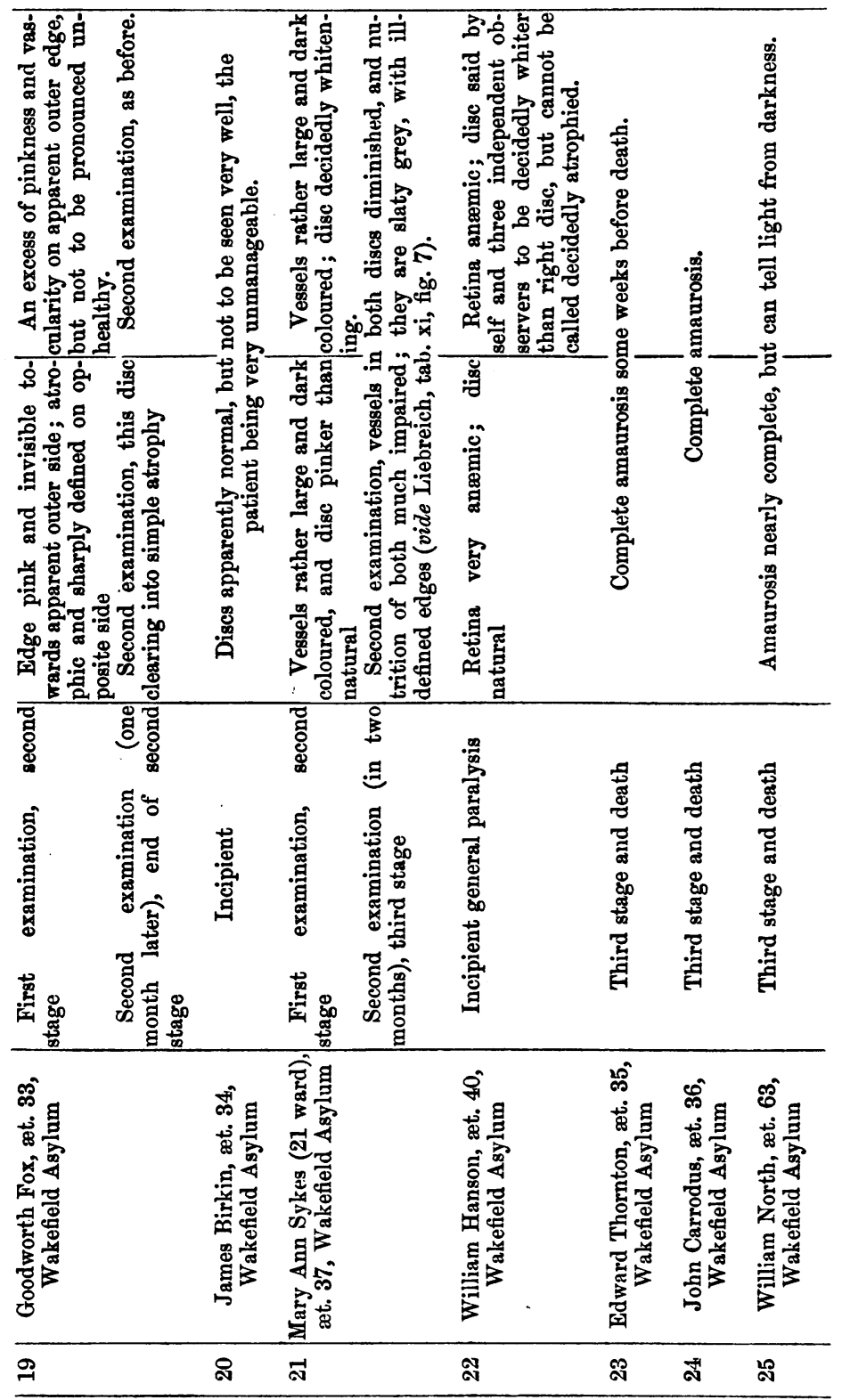




\begin{tabular}{|c|c|c|c|c|c|c|c|}
\hline 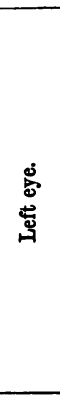 & 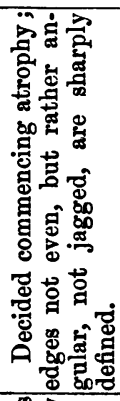 & 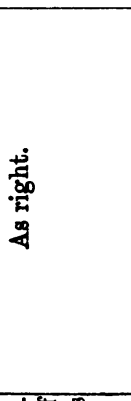 & 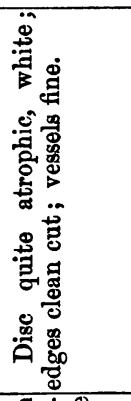 & 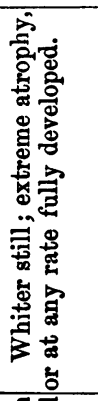 & \multirow{2}{*}{ 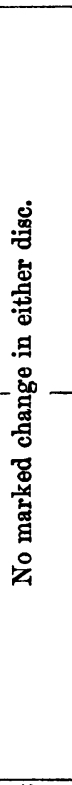 } & \multicolumn{2}{|c|}{ 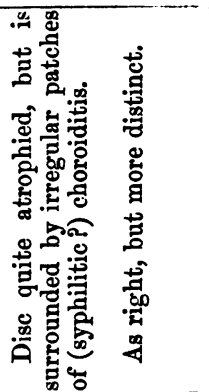 } \\
\hline 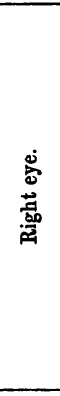 & 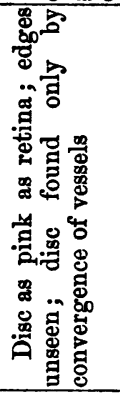 & 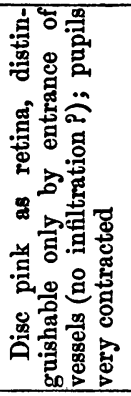 & 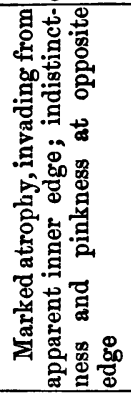 & 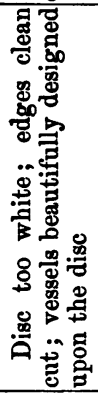 & & 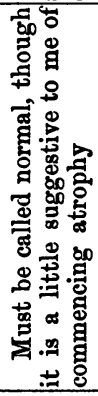 & 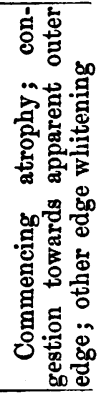 \\
\hline 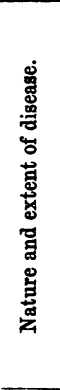 & 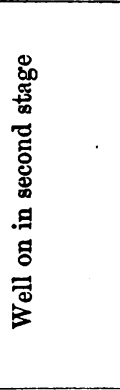 & 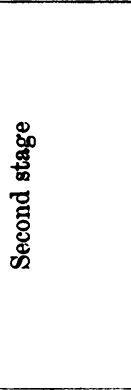 & 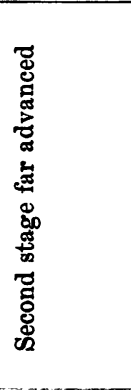 & 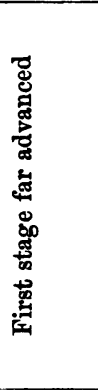 & 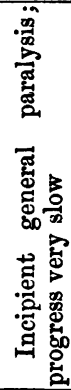 & 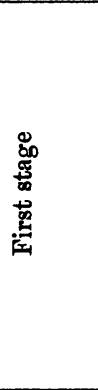 & 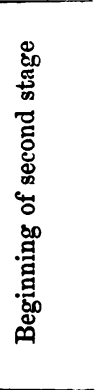 \\
\hline 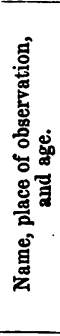 & 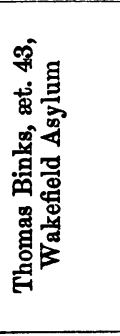 & 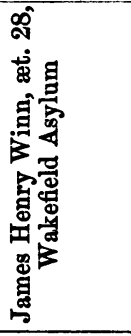 & 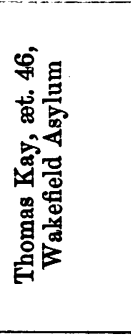 & 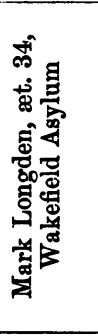 & 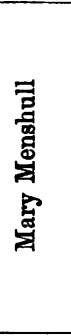 & 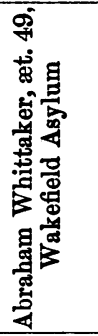 & 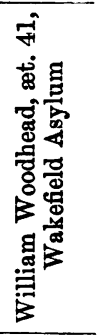 \\
\hline & \&్రి & ลे & : & สి & ధి & $\bar{\omega}$ & జ్ \\
\hline
\end{tabular}


AS SEEN IN THE INSANE.

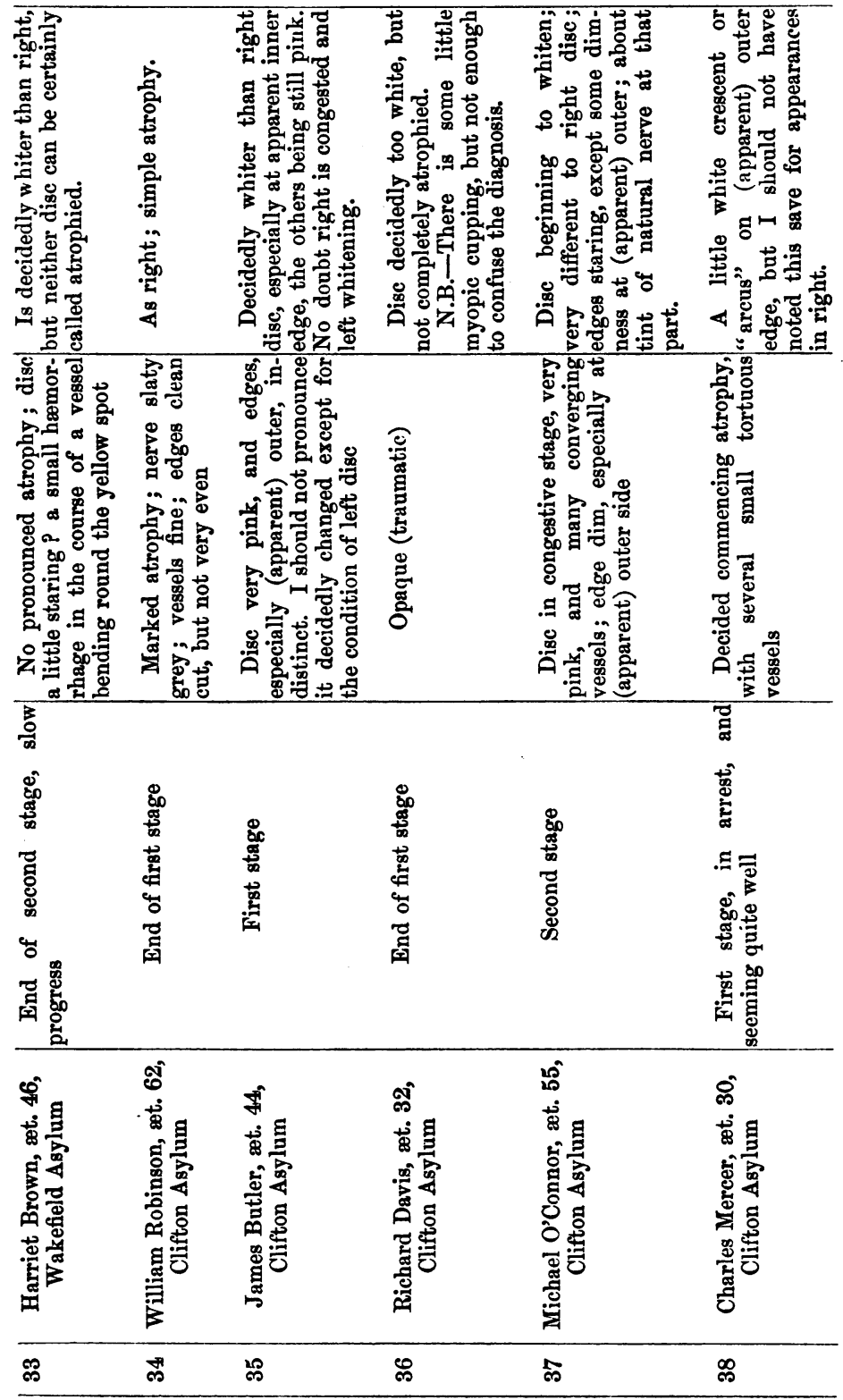




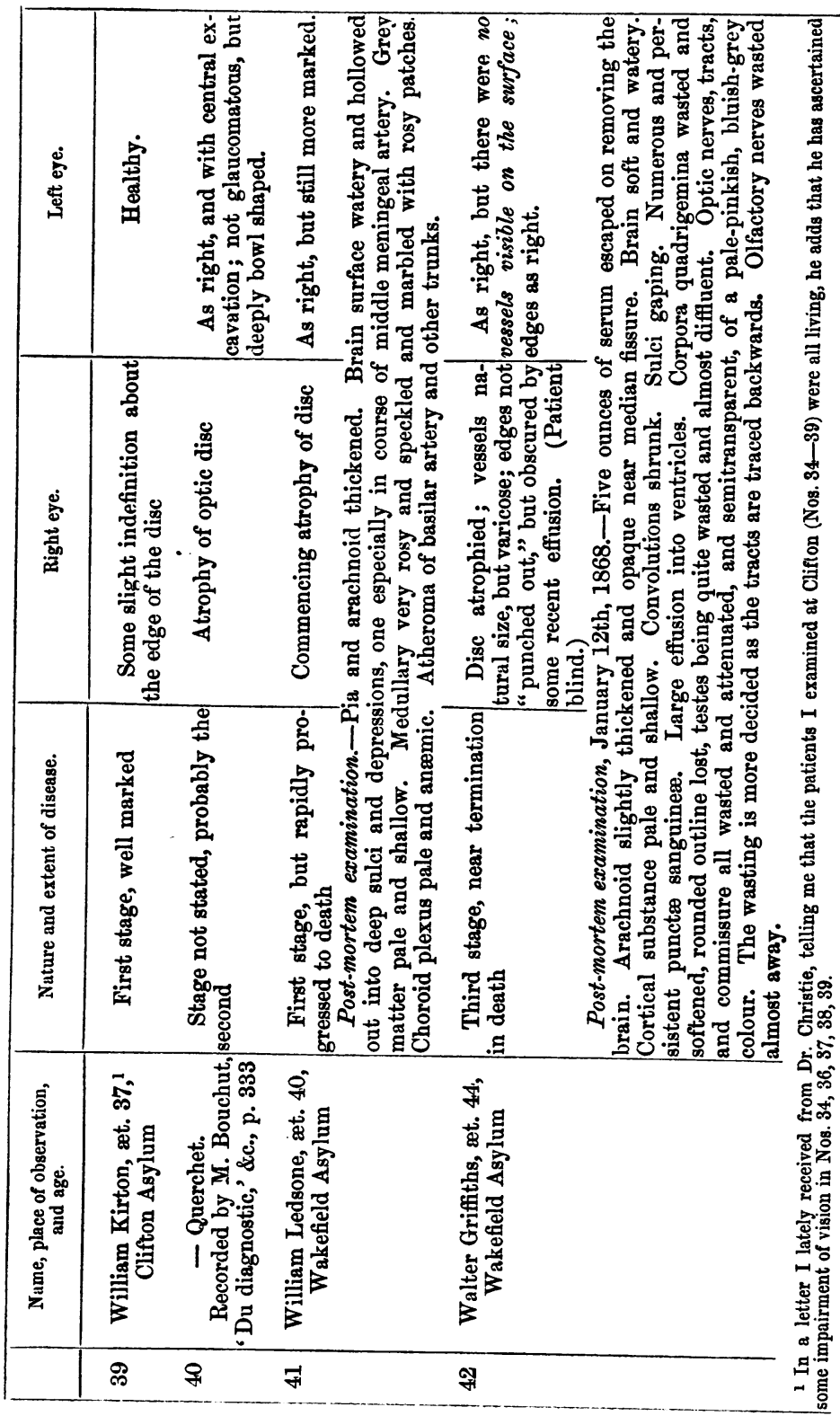


AS SEEN IN THE INSANE.

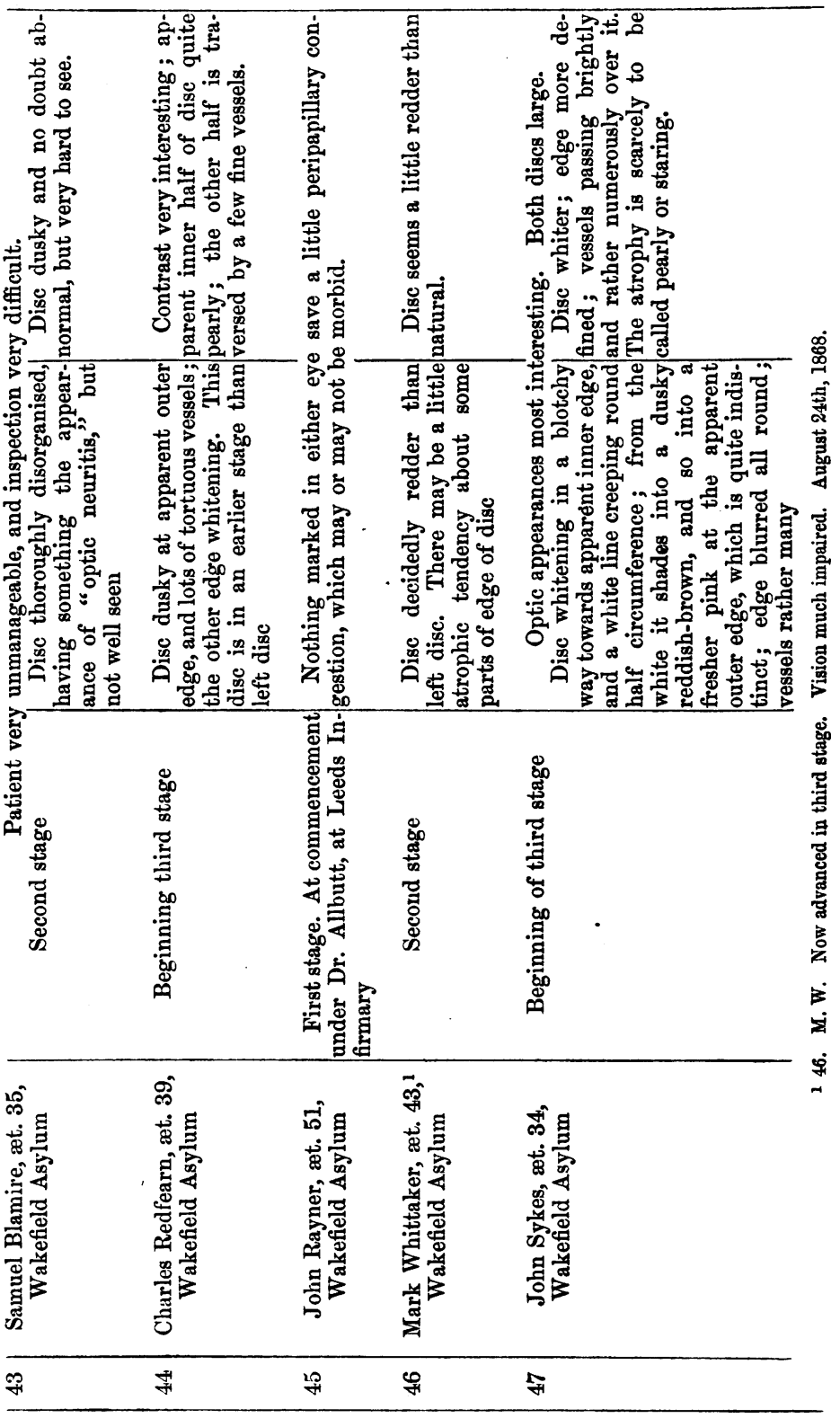




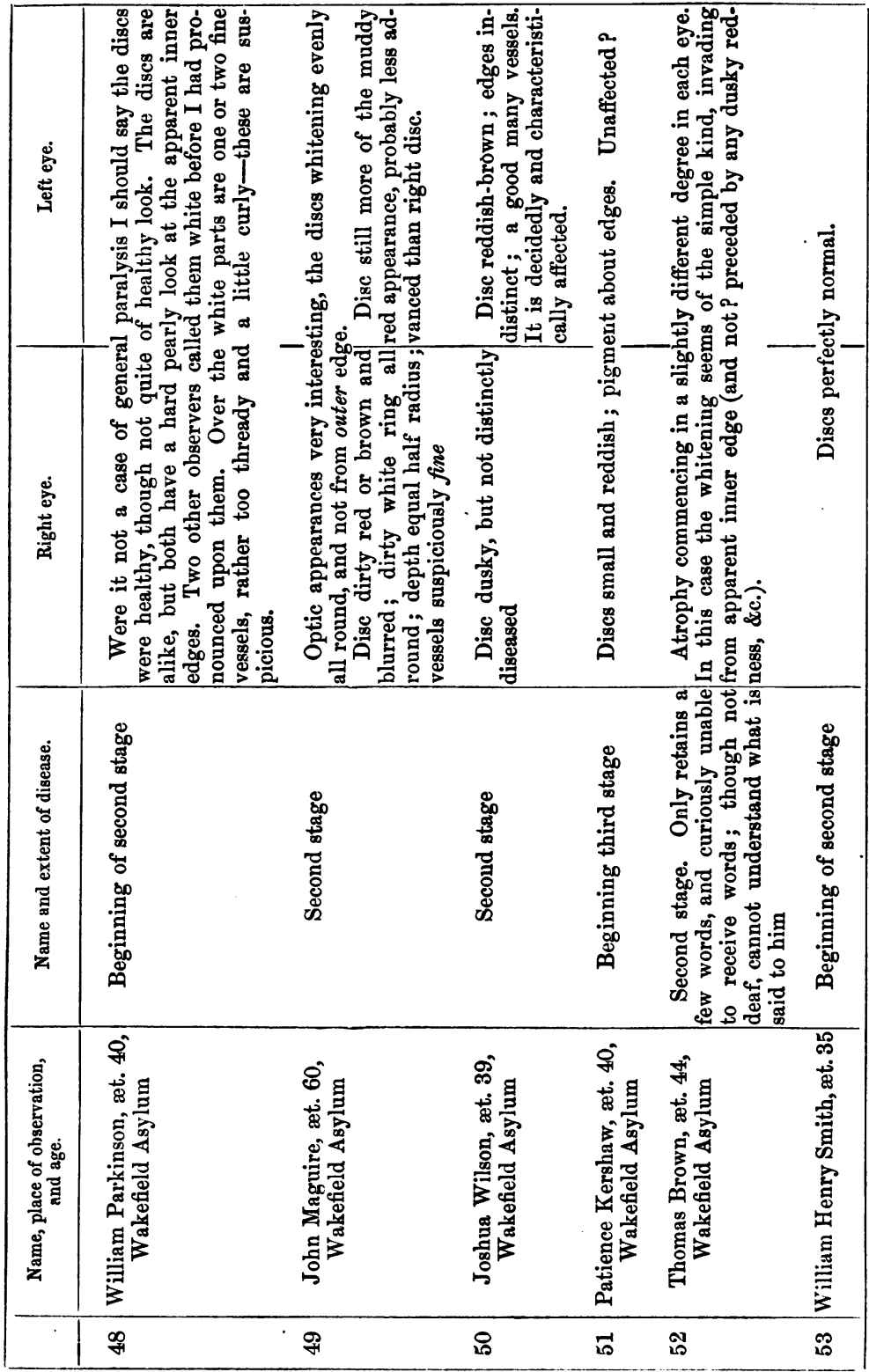


I have scheduled 53 cases of general paralysis, in 5 of which I find no change in the optic nerve and retina.

Of the remaining 48, I find atrophy of the optic disks in it's various stages in 41 cases, and 7 cases must be marked as doubtful. In all doubtful cases I made two or three examinations at intervals of a few weeks.

I note the following points :

1. That atrophy of the optic nerves takes place in almost every case of general paralysis, and, I may add, of the olfactory nerves also.

2. That it travels slowly down from the optic centres and along the tracts, becoming evident to the ophthalmoscope at about the end of the "first stage." 1

3. It becomes apparent as a hyperæmia of the nerve with slight exudation, but without much stasis—as a " red softening," in fact. It then whitens, generally from the real outer edge inwards, the nerve becoming white and staring, and its edge sharply defined. (Sometimes it takes a slate colour. Vide Liebreich, pl. xi, figs. 6, 7, 8, 9.)

From Case 38 it appears that the smaller vessels become fine and very tortuous before they vanish. If there has been decided exudation, the edges are, for a time, uneven, but the "punched-out" look always establishes itself in the end.

This kind of "white atrophy" may, in general paralysis, be watched throughout with great accuracy. Ophthalmic surgeons are rarely called upon to examine an optic nerve in the earliest stages of its failure, as these stages are not generally attended with marked loss of vision. They are, therefore, more familiar with the latter or white stages. The process I have above described may be called chronic optic neuritis, as opposed to the state commonly known as optic neuritis, a more highly vascular condition with great exudations, passing on into a more ragged and crushedlooking atrophy, which again, however, after a long period of time, may end in the clean-edged form.

1 Such was my opinion at the time when this paper was read. Since that time I have made a large number of sections of the optic tracts and tubercula quadrigemina in cases of general paralysis, and have been led to the opposite conclusion. 
4. The atrophy of the nerve seems to bear no fixed proportion to the ataxy of the orbital muscles seen in general paralysis. This ataxy is probably dependent upon the same causes as the ataxy of the articulating and other muscles.

5. The nerve changes are generally proportionate to the well-known contraction and dilatation of the pupils. These contract in the early or hyperæmic stage, and dilate as white atrophy succeeds.

6. As atrophy of the optic nerves can seldom be surely ascertained in the incipient stages of general paralysis, its diagnostic significance, therefore, is not great. Its value lies rather in its important pathological significance.

\section{Appendix to Cases of General Paralysis.}

Dr. Browne has been kind enough to forward to me a report of such autopsies as have taken place upon any of the above cases, viz. upon Nos. 3, 4, 10, 12, 14, 18, 19, 33, 47. In all, the membranes were found thickened and the convolutions wasted and water-logged. In all but two atheromatous disease of the arteries is noted.

In No. 3. The corpora striata, thalami, and corpora quadrigemina were "flattened, as if wasted."

In No. 4. "All the cerebral nerves much wasted; the optic nerves, commissure, and tracts, especially, atrophied."

In No. 14. "The optic thalami flattened, as if wasted."

In No. 18. " Corpora quadrigemina flattened, wrinkled, and softened ; cerebral nerves also softened."

In No. 47. "Optic nerves, commissure, and tracts, white, flattened, and wasted."

P.S.-Since this paper was in type No. 26 has died, and, in addition to the usual changes in the membranes and convolutions, the optic nerves were degenerated. Dr. Browne says, "the nerves appeared quite plump and round, and I should have reported them as healthy but for their white glistening appearance [white atrophy, T. C. A.]. On examination they were quite without consistence, and were chiefly made up of connective tissue and watery fluid." 
Of mania I have noted 51 cases. Of these, the state of the nerves was, in 25 cases, symptomatic of intracranial disease; in 13 cases it was of doubtful meaning; and in 13 cases I found either no changes at all or only local changes, such as glaucoma, myopia, \&c. I think the Society will be surprised to hear of symptomatic change being found and suspected in so large a number of cases. It was far more than I looked for. But it will be remembered, on the other hand, that the patients submitted to me were always wellmarked cases of disease, and in the larger proportion of them organic disease was suspected on grounds independent of my conclusions. From my list of mania cases I propose the following points for future observation :

1. That symptomatic changes in the eye are to be found in a large proportion of cases of mania.

2. That if cases known to be functional only, or incorrectly named (such as erotomania, transient mania, hysteria, \&c.) be omitted, the proportion of cases presenting permanent change in or near the optic discs is still larger.

3. That both in mania depending upon organic causes and in functional mania the back of the eye, if observed within a few days after a paroxysm, presents a vascular suffusion or pinkness, a pinkness so great after severe paroxysms as to obscure the disc. No exudation is seen in these cases, unless there exist some permanent mischief.

4. That during the paroxysm, on the contrary, the disc is anæmic, perhaps from spasm of the vessels.

5. That the permanent changes in the disc are due either to stasis from obstruction to the intracranial circulation, with consecutive atrophy; or to ramollissement ending in simple white atrophy; or they may present changes of a mixed character.

I may make a few further remarks upon my propositions concerning the hyperæmia or blush of the optic disc and retina in mania. I found this so frequently in maniacs who had recently passed through a paroxysm that $I$ began to think I could detect cases of mania by this appearance only. However, I carefully avoided any theorising during my inves-

vol. LI. 
tigations, lest I should unwittingly vitiate my observing powers. On reading my lists over, however, it occurred to me that this suffusion, which I also saw sometimes upon the conjunctiva, might be due to a paralysis of the vaso-motor nerves.

I instantly turned to the notes of a case which I had by good luck been able to observe during a paroxysm, a piece of rare good fortune.

The Society will see that I have there noted an anæmic retina, and a whitish state of the disc which I put down to commencing atrophy, though with some doubt. May there be in the eye, and so in the brain, a spasm of the arteries-an epilepsy of the mental functions-followed by a paralytic dilatation of longer or shorter duration? Of course my one case can be nothing more than a suggestion of such a mode of action. The appearances of excessive vascularity seemed to last, on an average, from five to eight days. I watched its fading in several cases. 
AS SEEN IN THE INSANE.

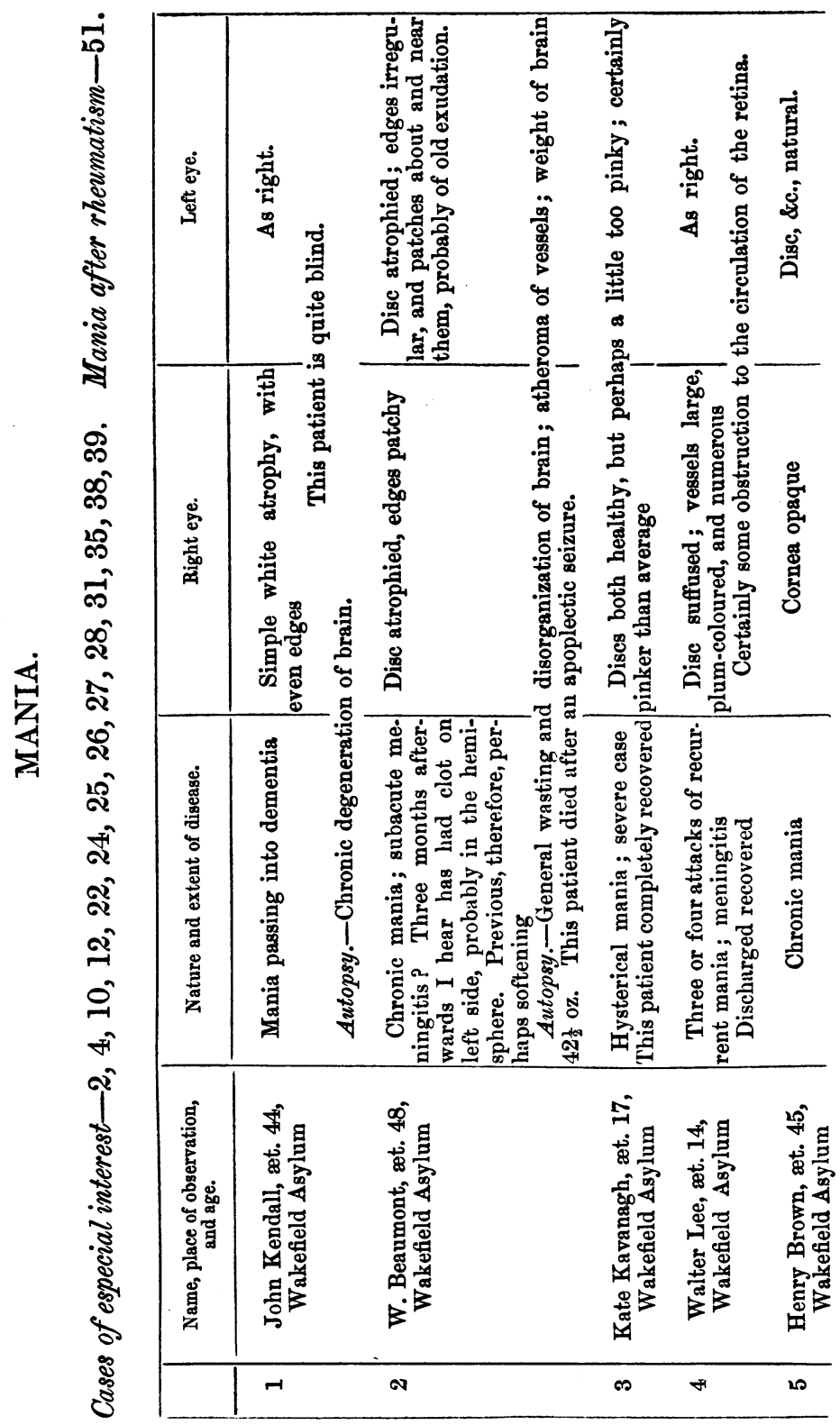




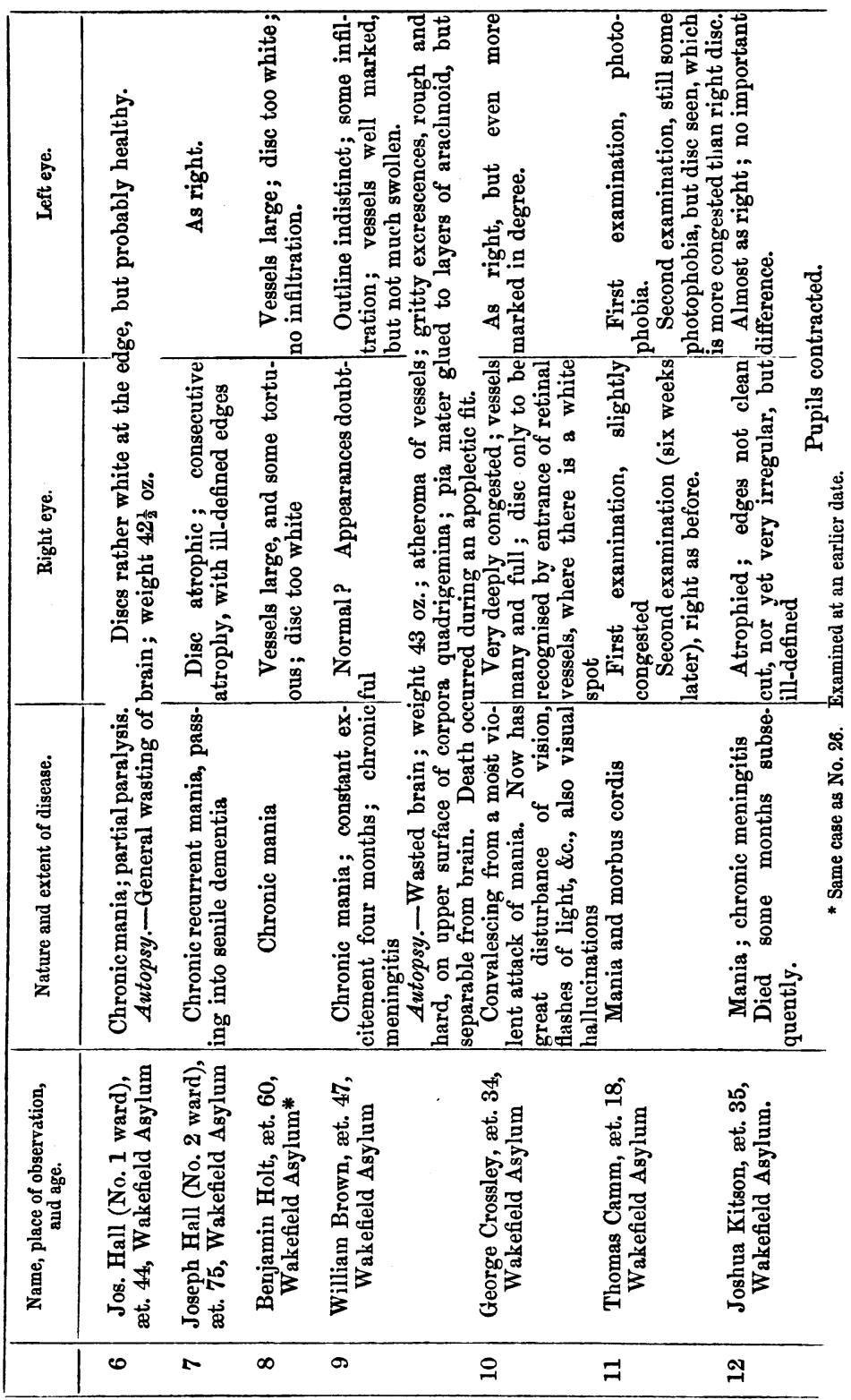


AS SEEN IN THE INSANE.

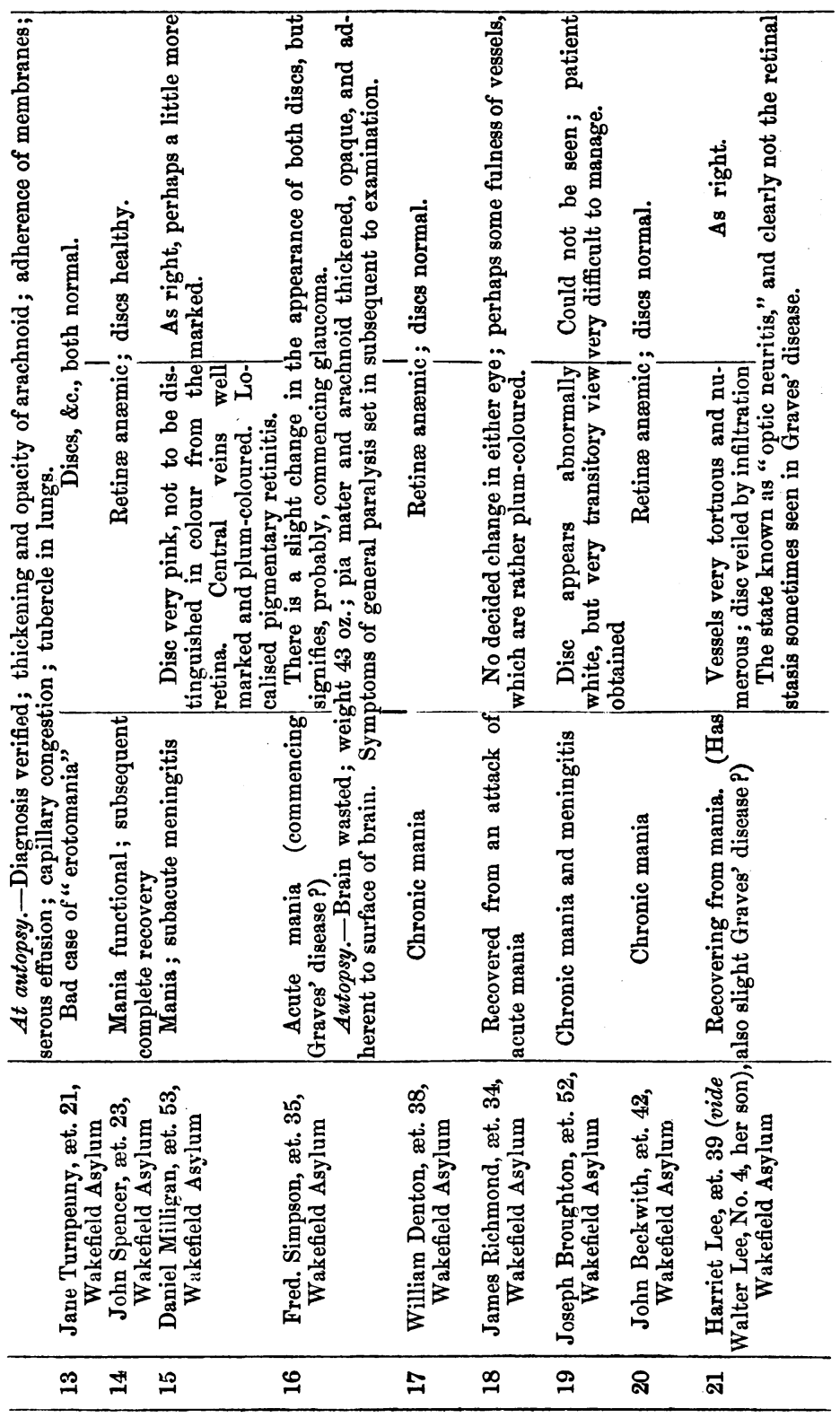




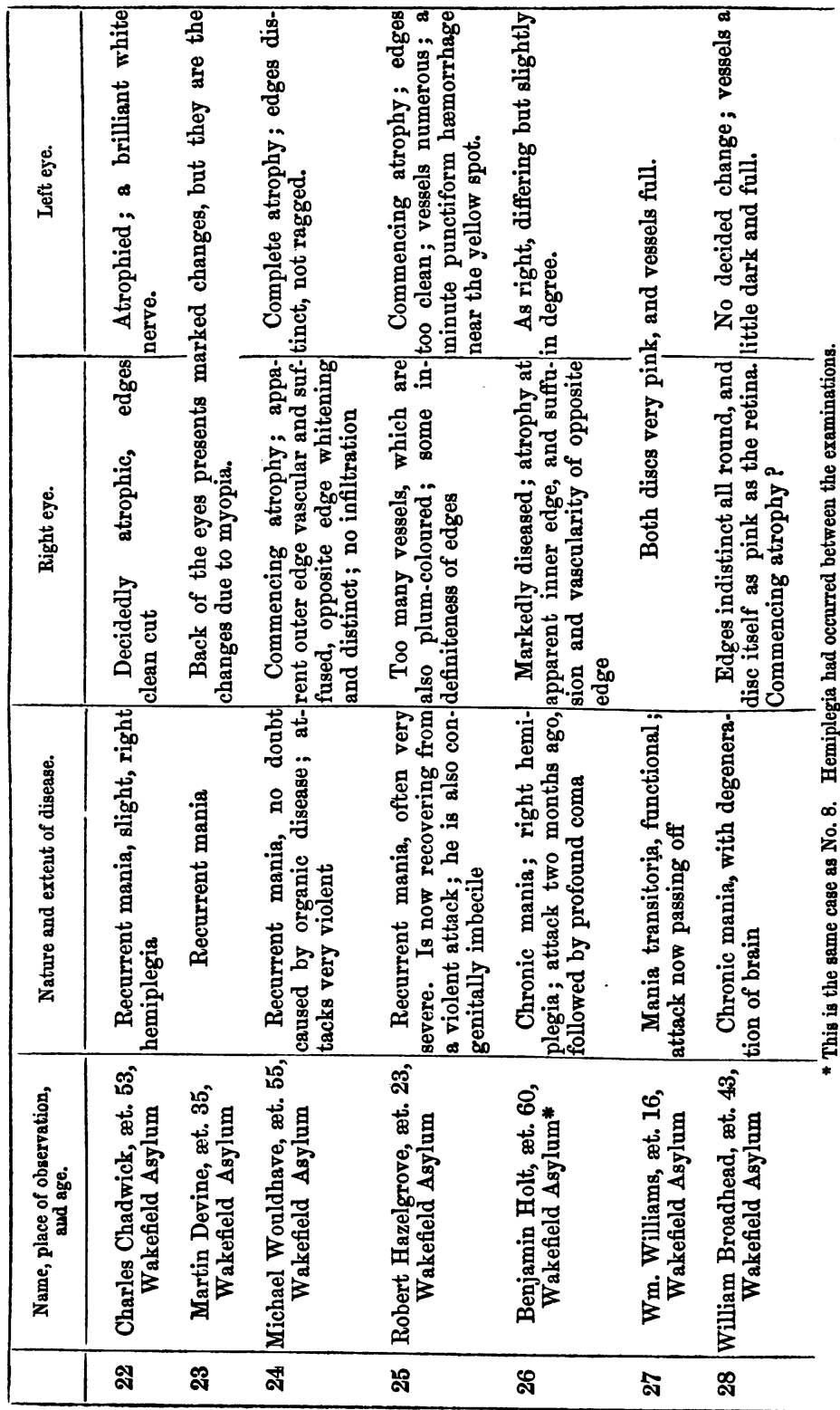


AS SEEN IN THE INSANE.

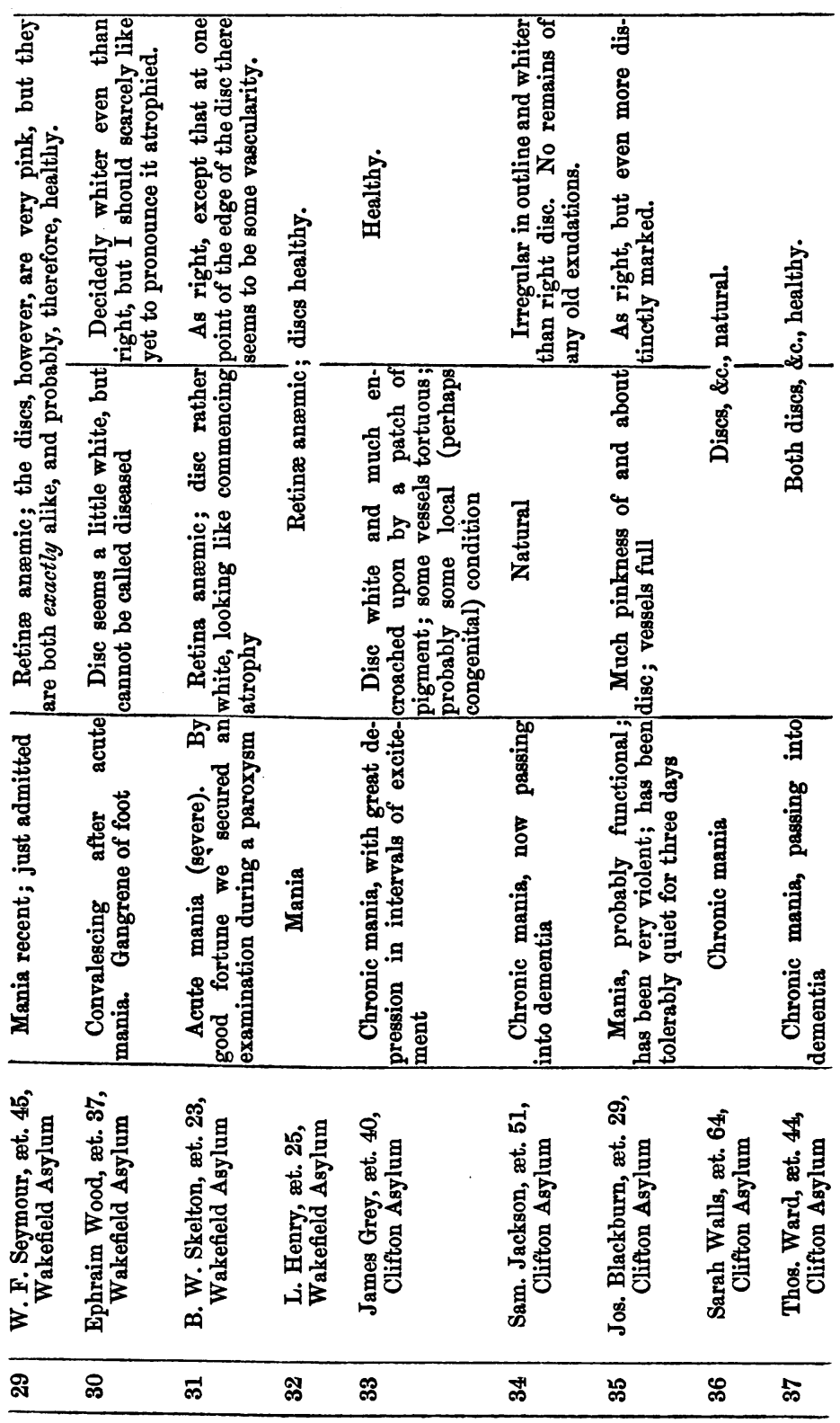




\begin{tabular}{|c|c|c|c|c|c|c|c|}
\hline 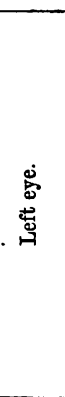 & 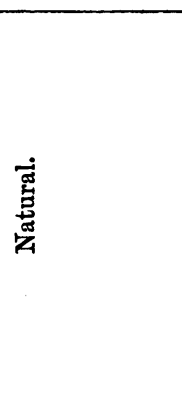 & 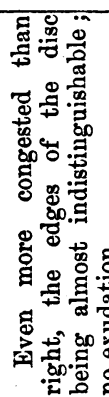 & 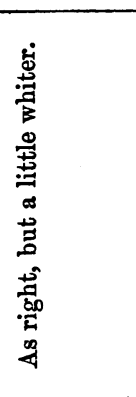 & 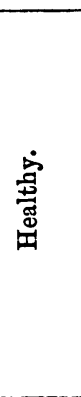 & 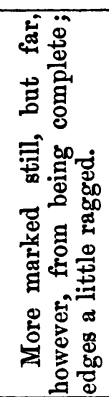 & 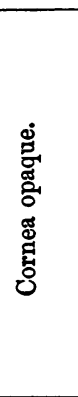 & 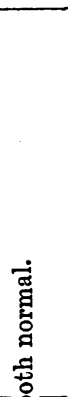 \\
\hline 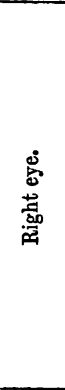 & 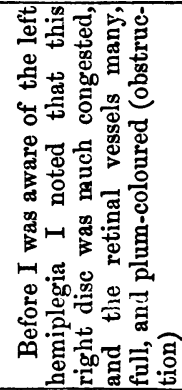 & 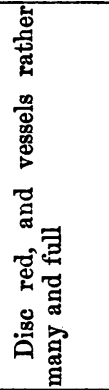 & 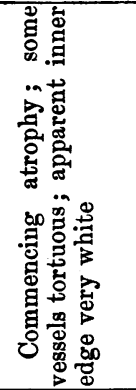 & $\begin{array}{l}\text { 疍 } \\
\text { 总 }\end{array}$ & 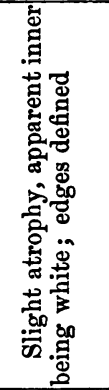 & 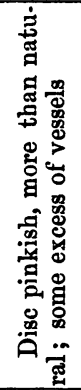 & D. \\
\hline 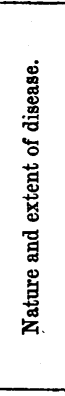 & 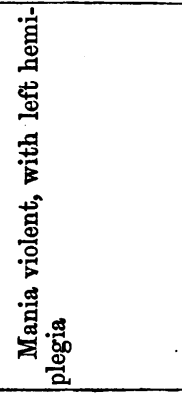 & 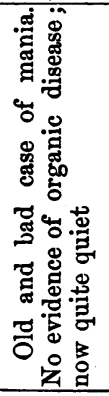 & 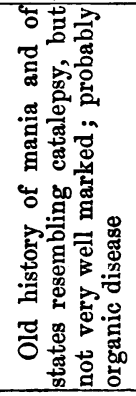 & 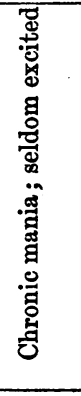 & 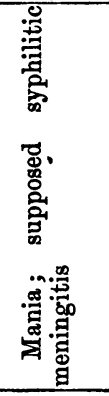 & 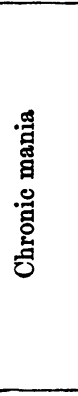 & 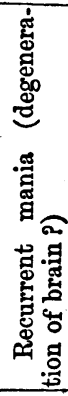 \\
\hline \multirow[t]{2}{*}{ 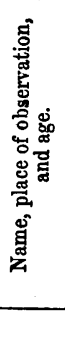 } & 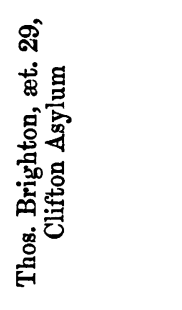 & 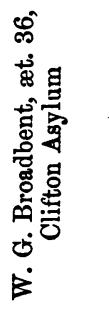 & 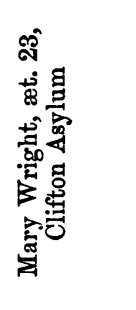 & 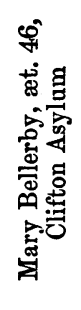 & 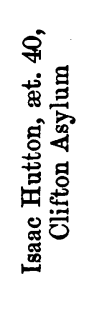 & 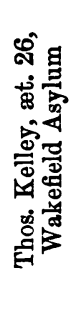 & 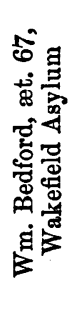 \\
\hline & 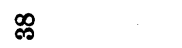 & ஜ̊ & 요 & $F$ & 과 & ஜ & 出 \\
\hline
\end{tabular}




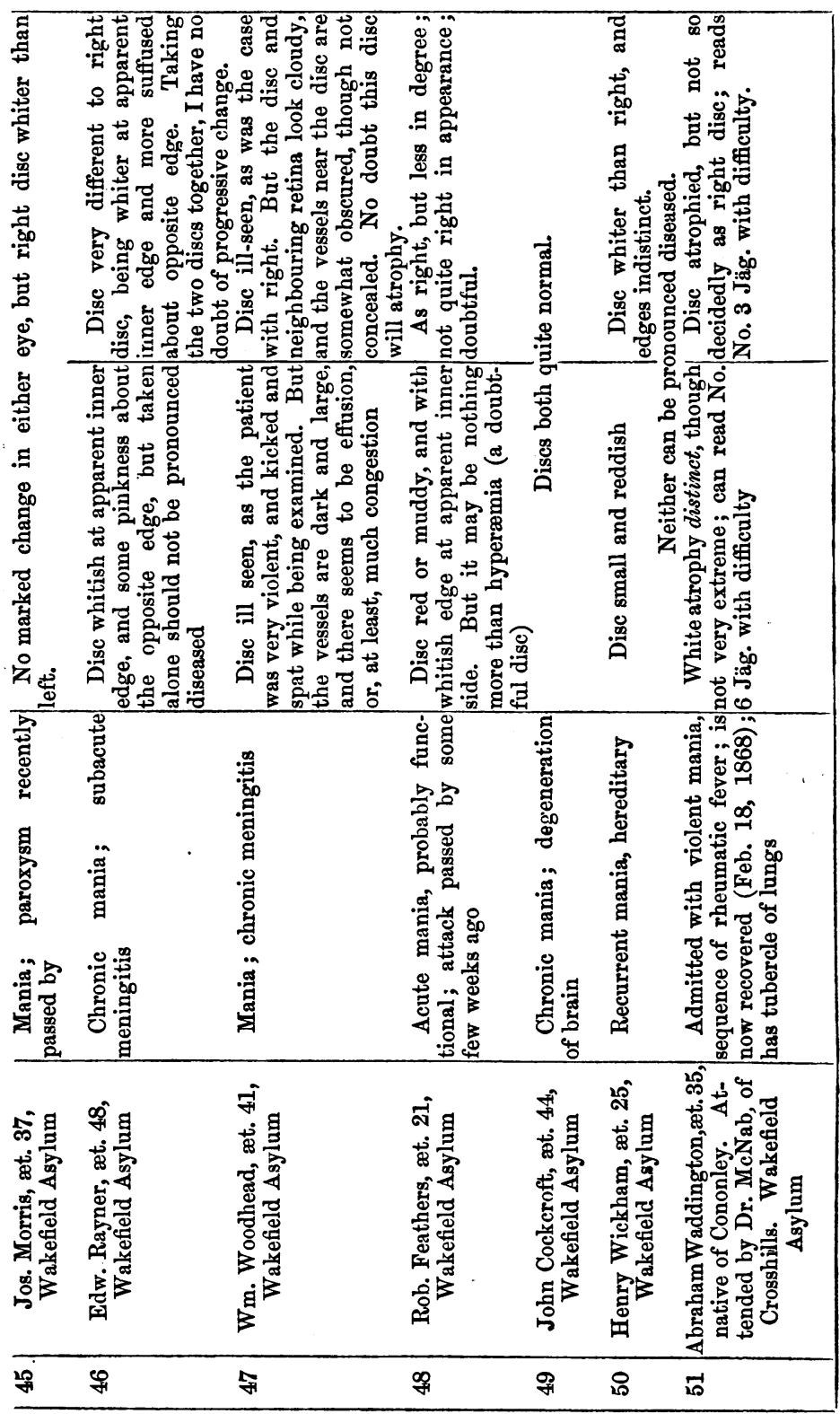


The next portion of my schedule contains 38 cases of dementia not connected with epilepsy. Most of them, however, were due to organic disease in the brain, and were picked out for their severity.

Of these $I$ found disease in the optic nerve or retina in 23 cases; I found 6 in a doubtful condition, and 9 were healthy. It will be seen that in simple acute dementia (uncomplicated with organic disease), however profound, no changes in the optic nerve are recorded.

I will only note further, that in dementia, where atrophic changes were seen by the ophthalmoscope, I both made inquiries concerning the sight, and, in some cases, tested it. I confirmed my former belief, that statements concerning visual power, whether made by patients, or by their friends, are of no value (vide Dementia, e.g. No. 29); and, moreover, that failure of sight, as tested by types, is wholly an oculist's symptom, and bears little proportion to the amount of atrophic or other disease that may be seen in the nerve. Mapping of the field of vision is a most important physician's symptom, but with lunatics this would have been simply out of the question. 
AS SEEN IN THE INSANE.

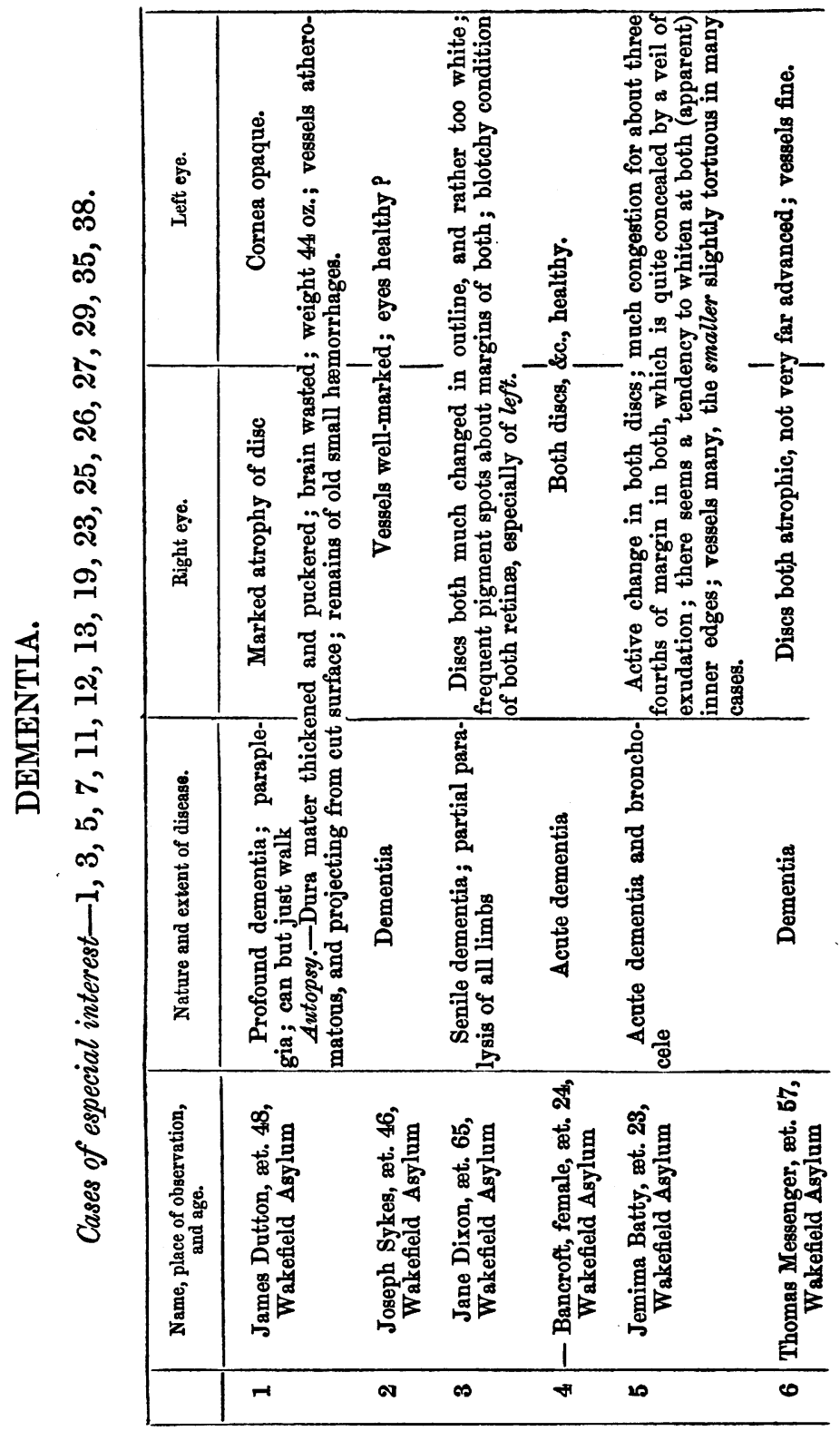




\begin{tabular}{|c|c|c|c|c|c|c|c|c|}
\hline 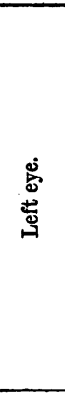 & 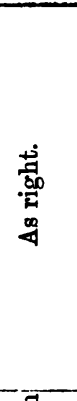 & 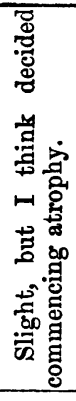 & 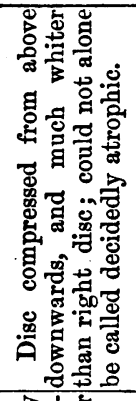 & 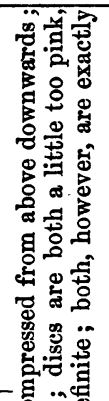 & 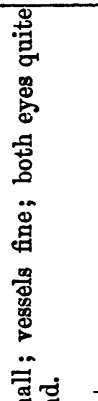 & 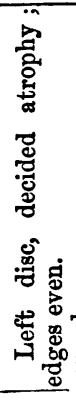 & 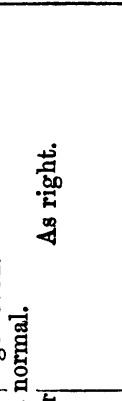 & 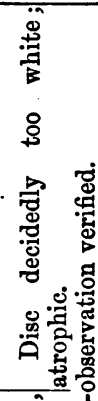 \\
\hline 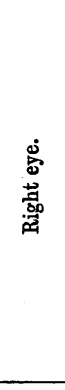 & 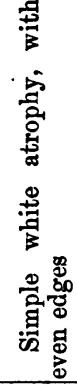 & 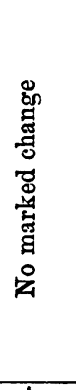 & 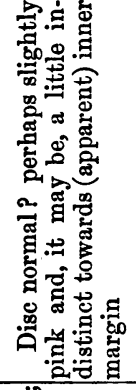 & 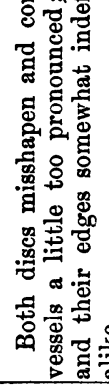 & 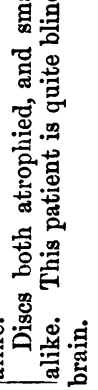 & 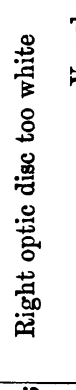 & 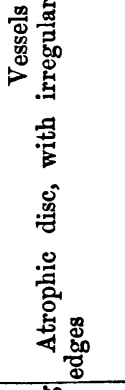 & 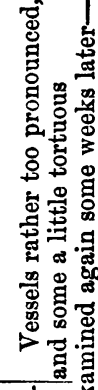 \\
\hline 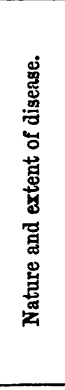 & 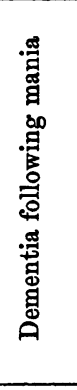 & 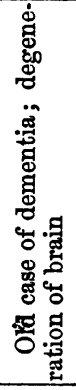 & 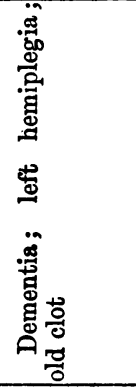 & 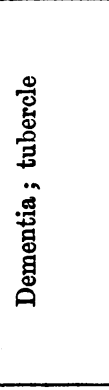 & 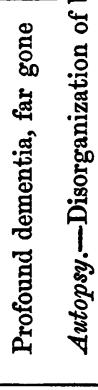 & 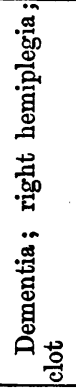 & 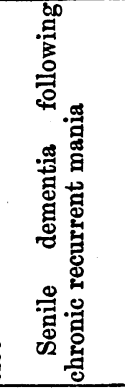 & 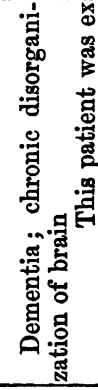 \\
\hline \multirow[t]{2}{*}{ 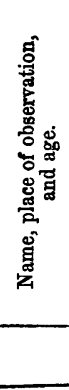 } & 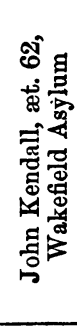 & 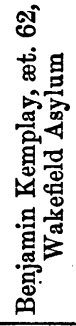 & 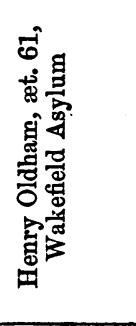 & 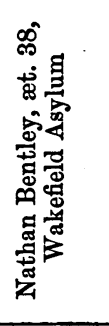 & 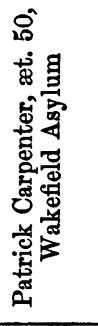 & 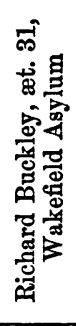 & 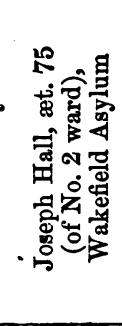 & 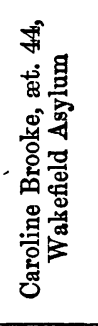 \\
\hline & & & & & & & & \\
\hline
\end{tabular}




\begin{tabular}{|c|c|c|c|c|c|c|c|}
\hline 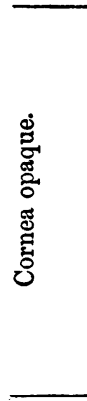 & 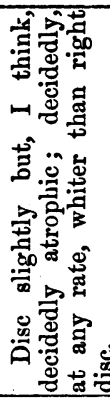 & 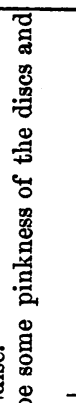 & 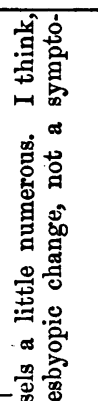 & 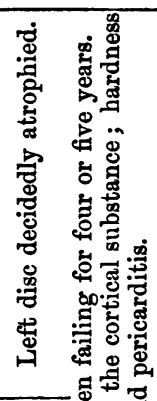 & 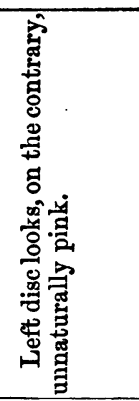 & 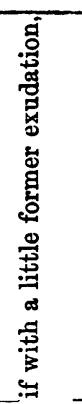 & 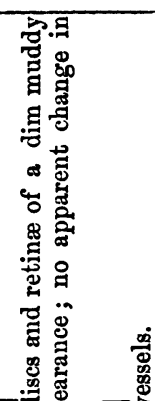 \\
\hline 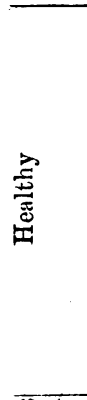 & 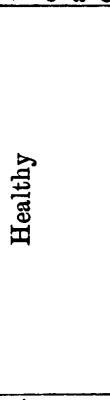 & 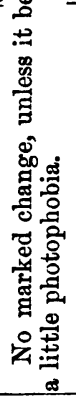 & 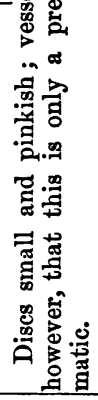 & 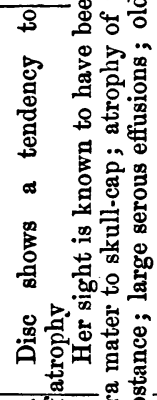 & 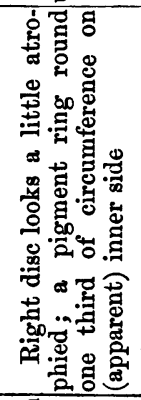 & 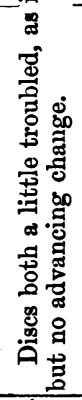 & 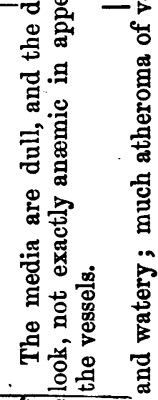 \\
\hline 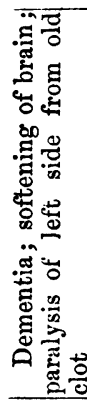 & 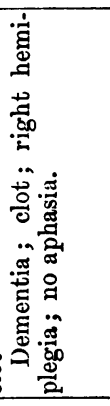 & 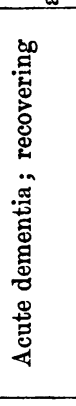 & 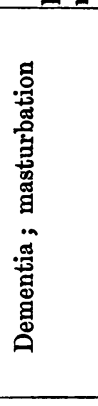 & 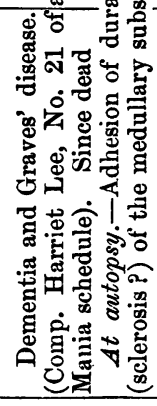 & 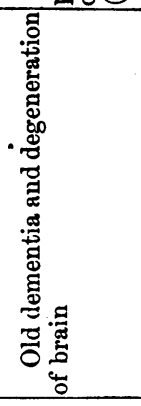 & 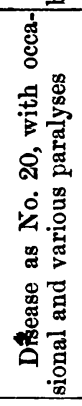 & 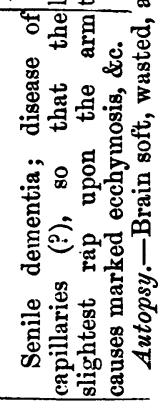 \\
\hline 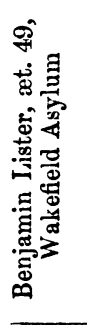 & 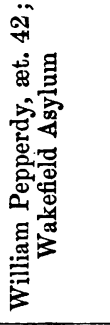 & 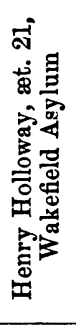 & 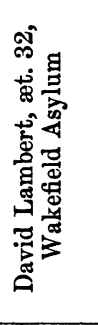 & 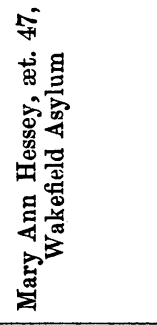 & 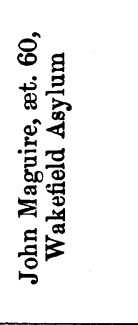 & 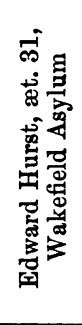 & 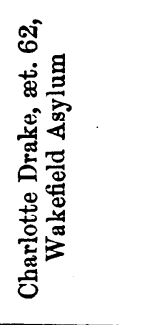 \\
\hline & $\stackrel{\leftrightarrow}{\mathscr{r}}$ & $\approx$ & $\stackrel{\infty}{-1}$ & م) & ః & ה & ๙ \\
\hline
\end{tabular}




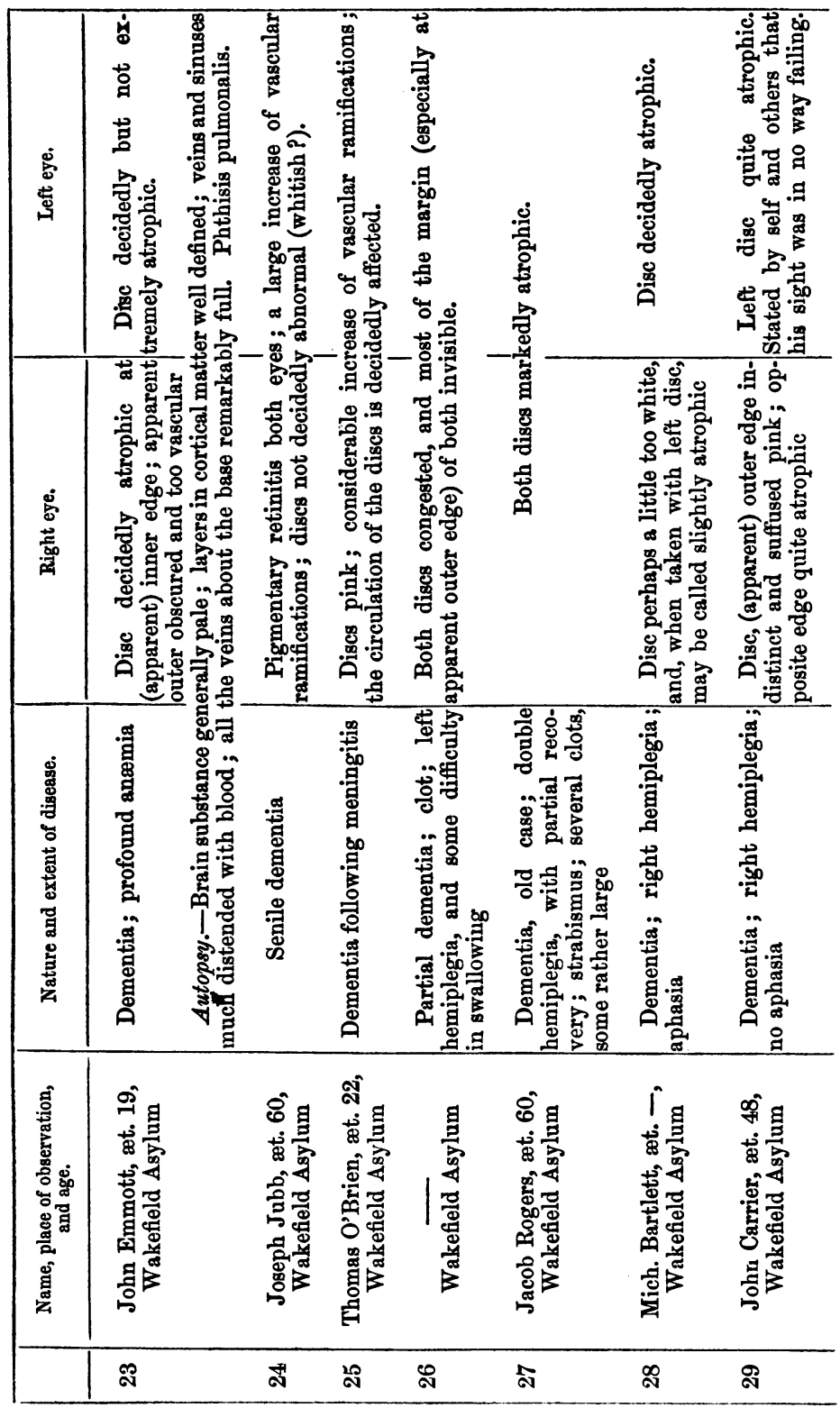


AS SEEN IN THE INSANE.

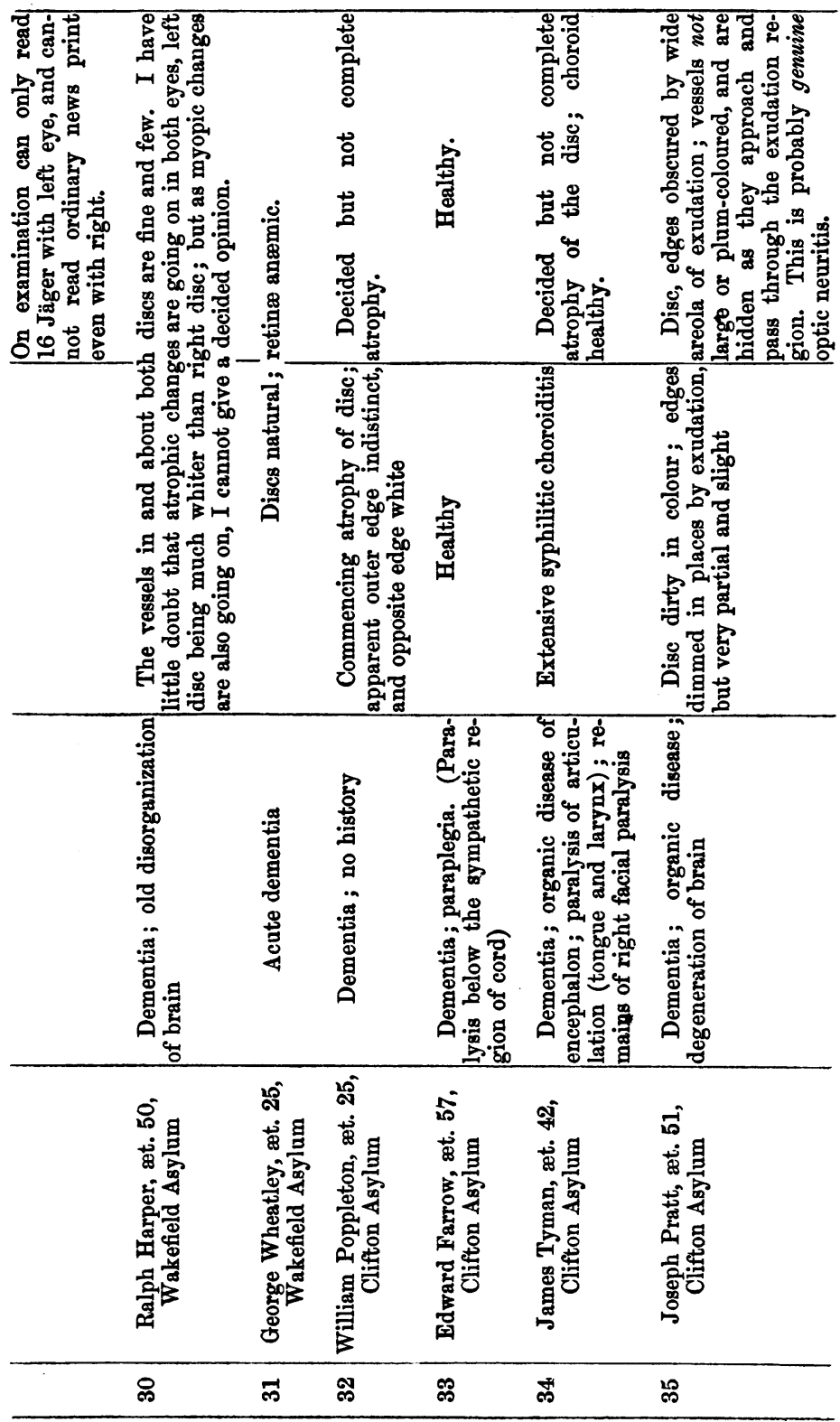




\begin{tabular}{|c|c|c|c|}
\hline 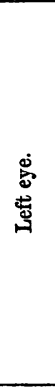 & 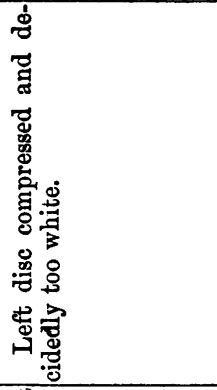 & 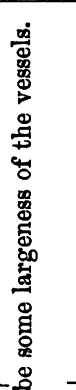 & 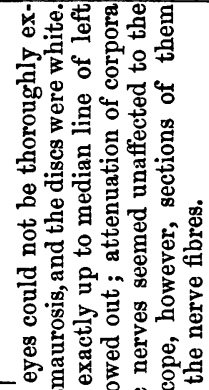 \\
\hline $\begin{array}{l}\text { 离 } \\
\text { 苛 } \\
\text { 离 }\end{array}$ & 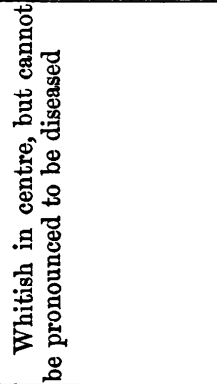 & 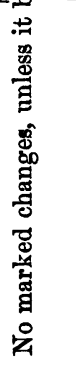 & 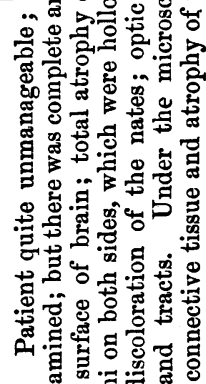 \\
\hline 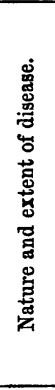 & 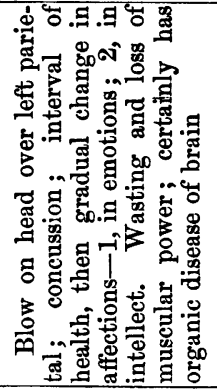 & 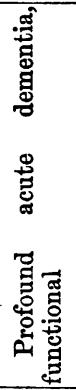 & 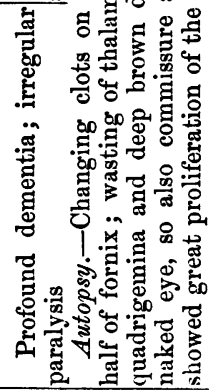 \\
\hline \multirow[t]{2}{*}{ 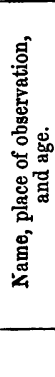 } & 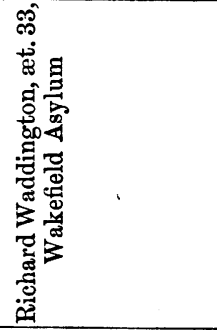 & 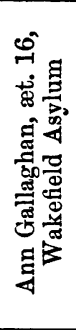 & 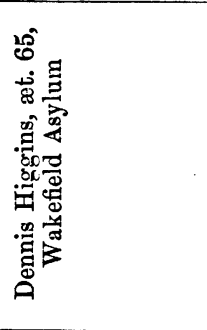 \\
\hline & ల్ల & ద్ర & ద్లో \\
\hline
\end{tabular}


In melancholia and monomania, which I have tabled together for convenience, the relation of events is changed. As a large proportion of these affections are functional only, so I find, on analysing my list, that of 17 cases, the optic nerve and retina were healthy in 10 , doubtful in 4 , diseased in 3 cases. Of the four marked as doubtful, the case of John Booth (No. 1 of the table), which is noted as possibly a case of commencing atrophy of disc, has since shown symptoms of locomotor ataxy, as Dr. Browne tells me. This event accounts for my suspicion of commencing atrophy. I find in the 3 diseased cases that Dr. Browne notes "atheroma of vessels" in one; in another "probable organic disease;" in the third, "chronic disorganization of the brain."

Alienist physicians will not be surprised to hear that I very frequently noted the presence of anæmia of the retina in melancholia. 


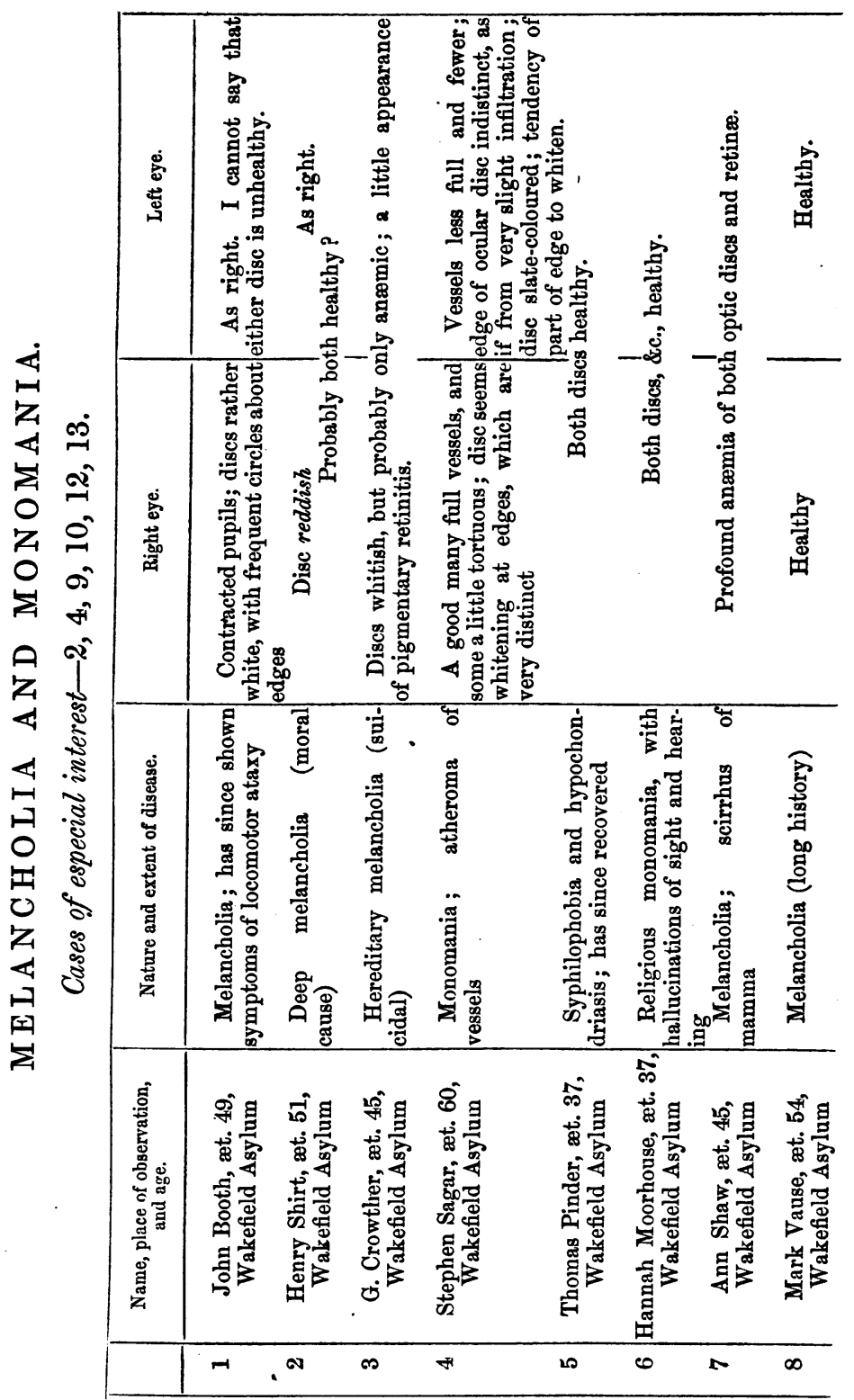


AS SEEN IN THE INSANE.

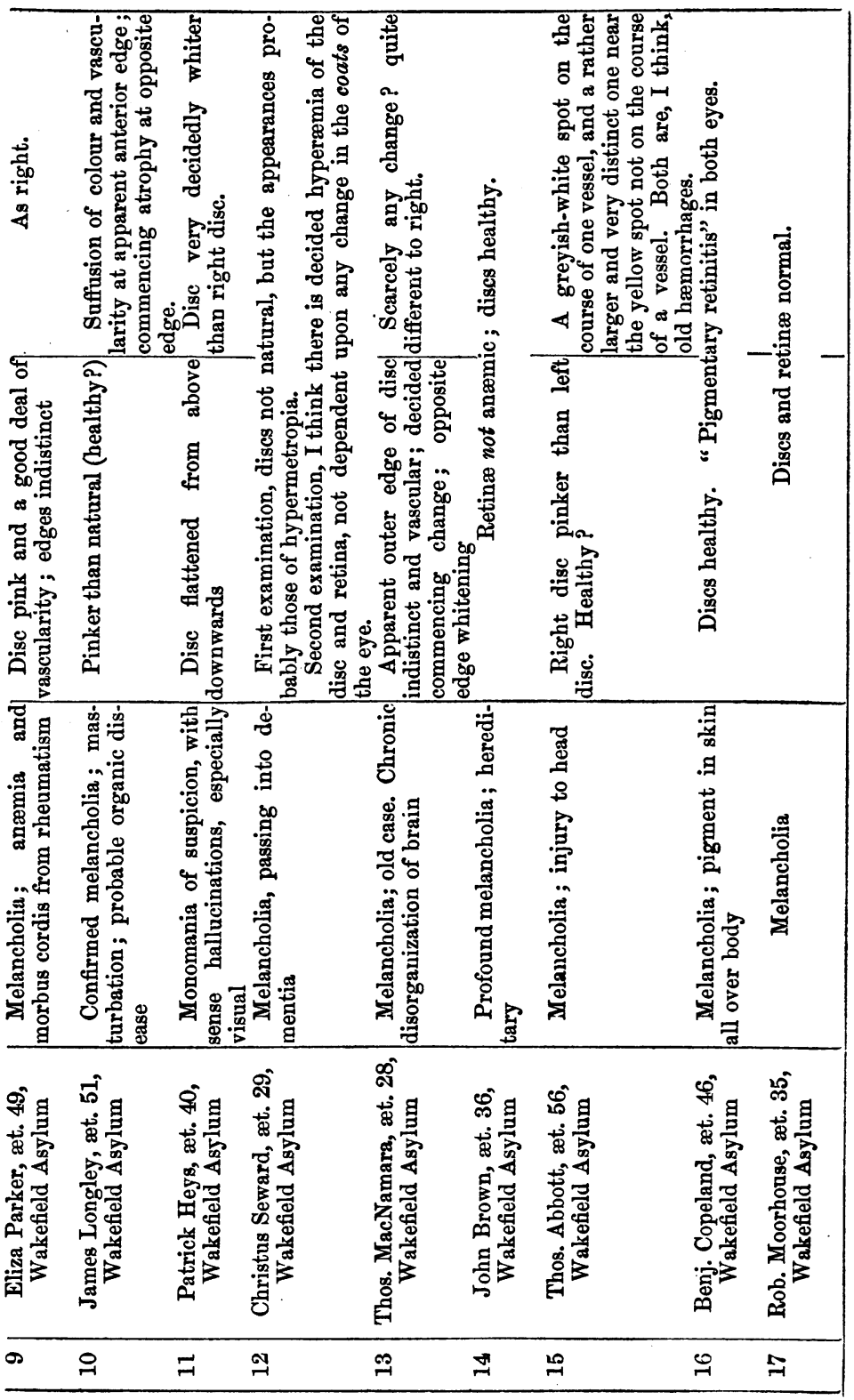


Of insanity depending upon epilepsy I bring 43 cases. It may surprise some of my hearers to be told that when compared with general paralysis, mania, and dementia, the proportion of epileptic cases which present symptomatic changes in the eye is small.

I note disease of the optic nerve or retina in 15 cases out of the 43. I mark 9 as doubtful; the remaining 19 showed no diseased change.

It is known, however, by those who have used the ophthalmoscope in cerebral disease that epilepsy alone (not dependent upon organic disease) is not usually accompanied by disease of the optic nerve. It is thought that some change in the vessels of the retina may be seen in epilepsy, and some of my cases seem to bear this out. On a re-examination of the table it will be seen that organic disease was known by unilateral symptoms, or otherwise, to exist in most of the cases in which the optic nerves are noted as diseased.

I should perhaps remind the Society that the general diagnoses and the eye examinations were noted by different persons. 
AS SEEN IN THE INSANE.

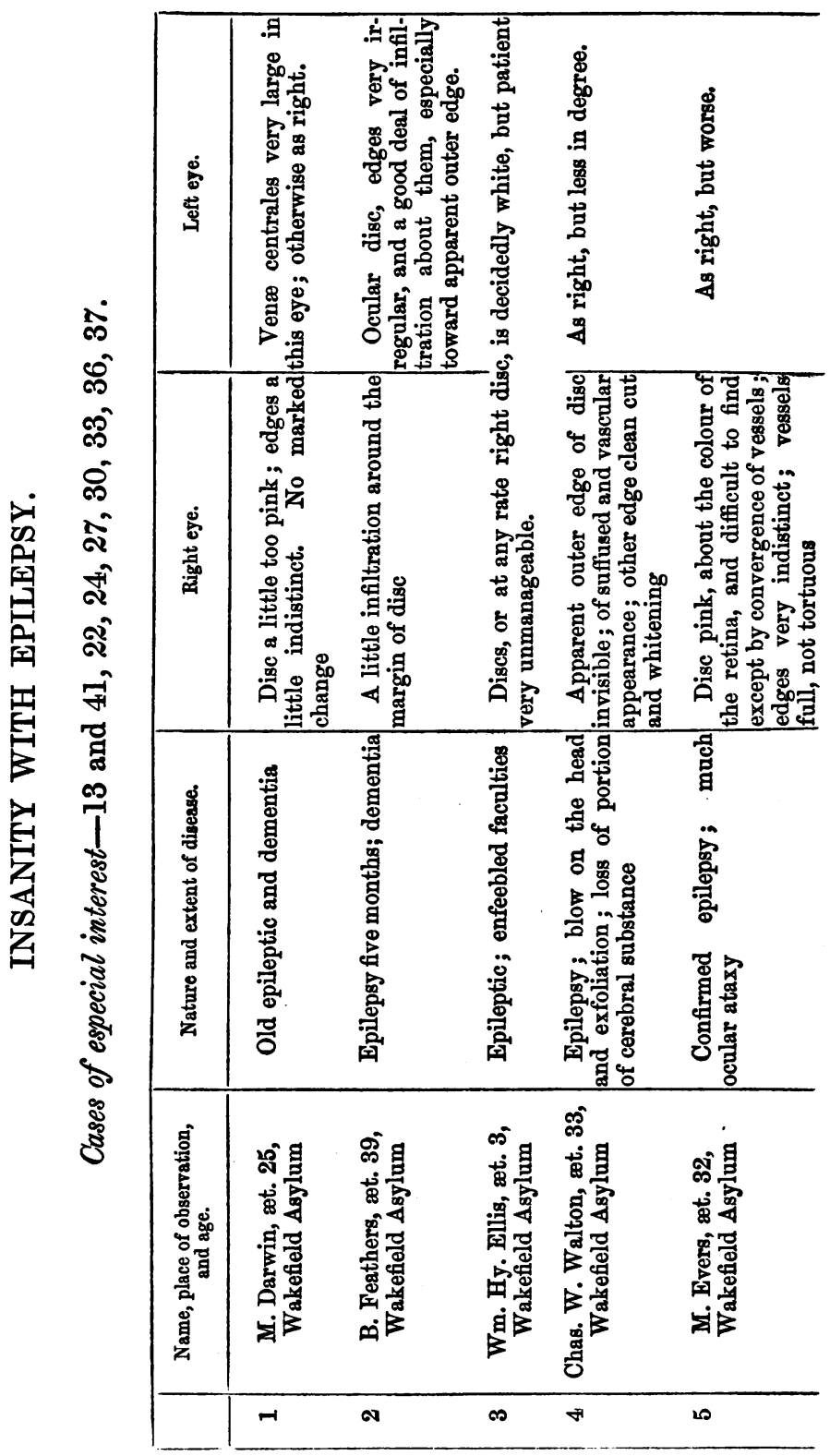




\begin{tabular}{|c|c|c|c|c|c|c|}
\hline 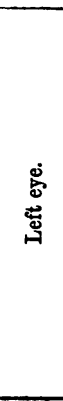 & 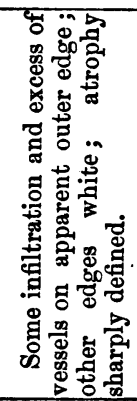 & 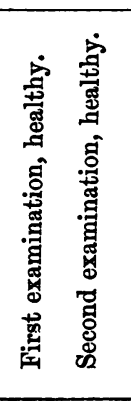 & 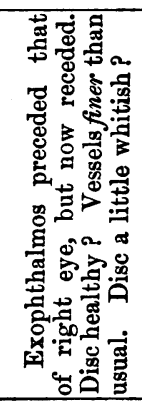 & 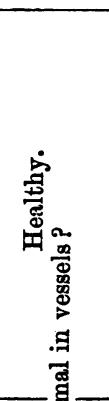 & 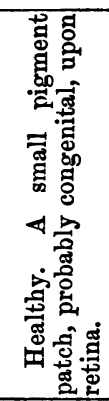 & 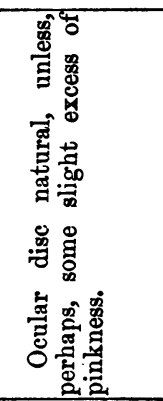 \\
\hline 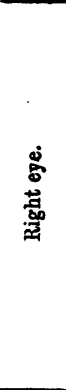 & 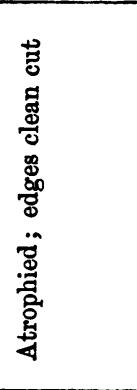 & 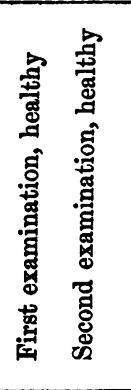 & 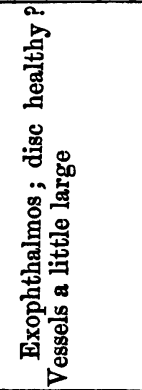 & 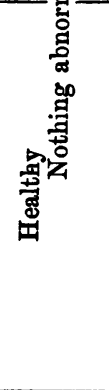 & 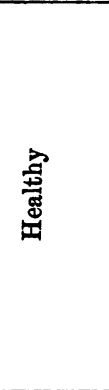 & 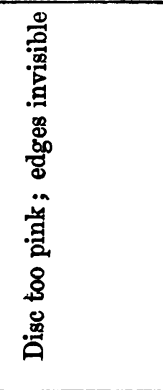 \\
\hline 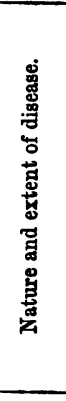 & 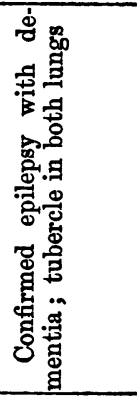 & 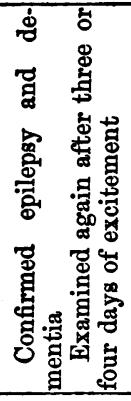 & 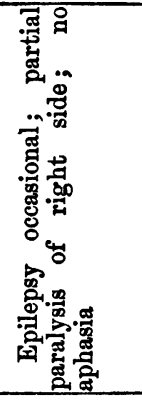 & 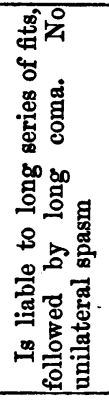 & 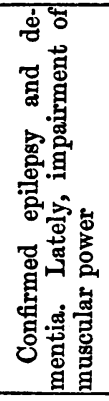 & 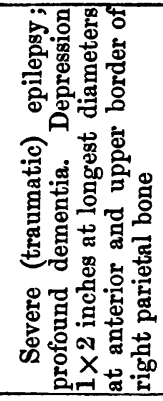 \\
\hline 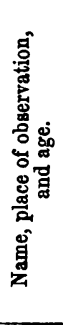 & 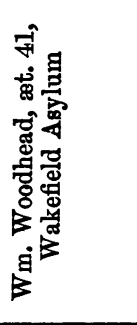 & 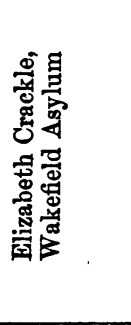 & 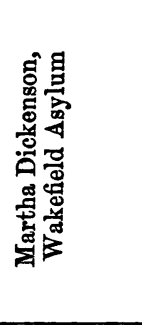 & 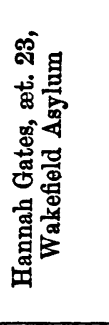 & 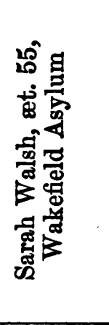 & 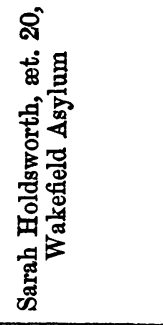 \\
\hline & 0 & N & $\infty$ & os & 요 & $\Rightarrow$ \\
\hline
\end{tabular}


AS SEEN IN THE INSANE.

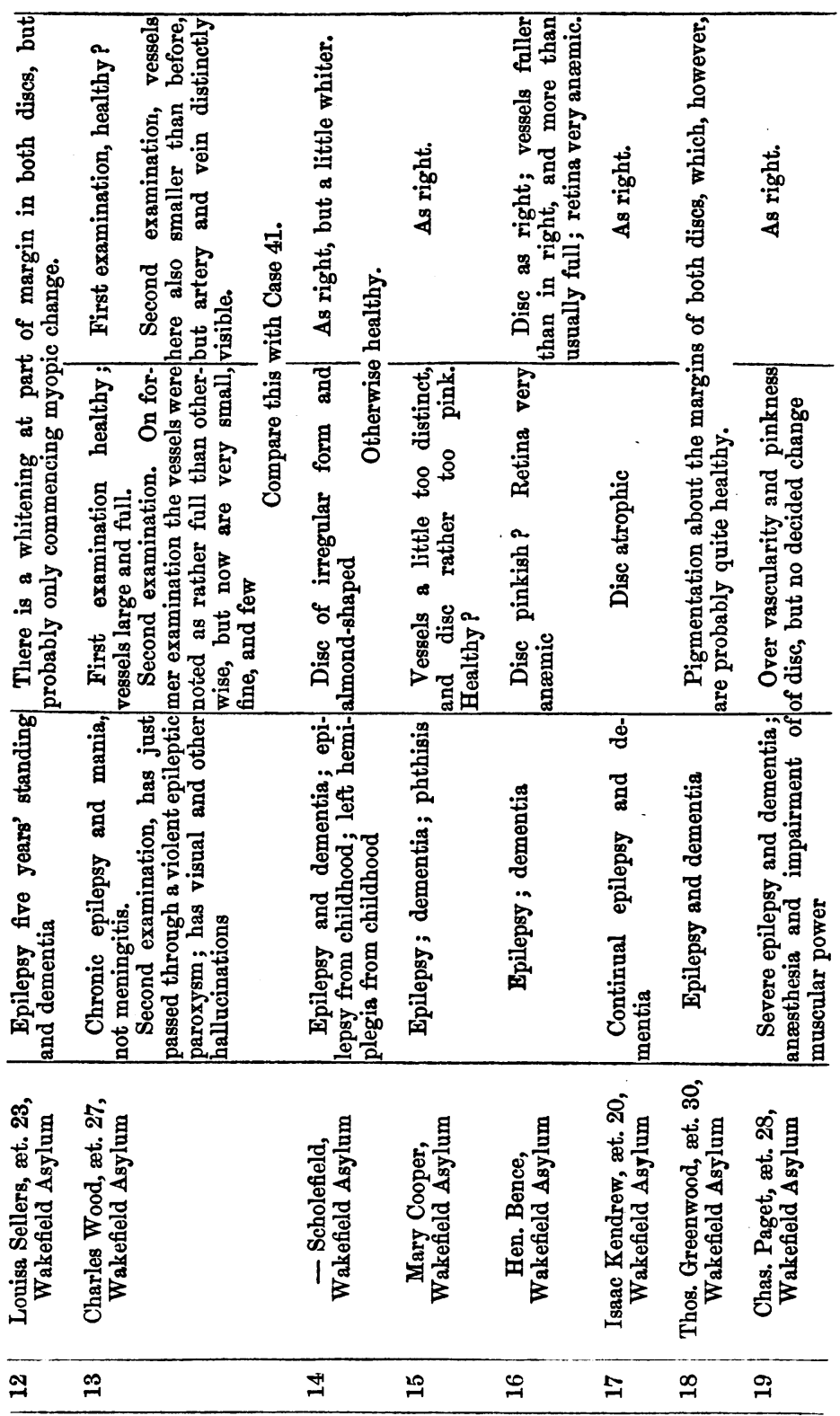




\begin{tabular}{|c|c|c|c|c|c|c|c|}
\hline 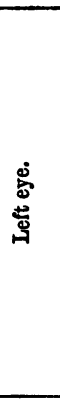 & $\begin{array}{l}\text { 密 } \\
\text { 蹗 }\end{array}$ & 害 & 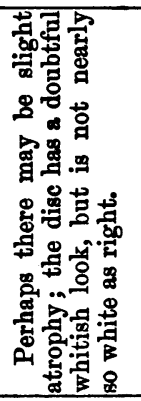 & 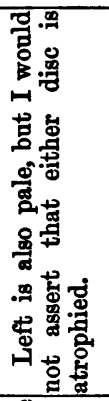 & 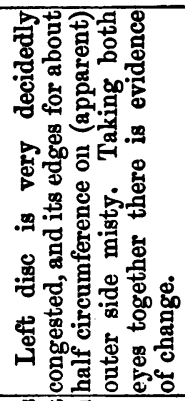 & $\begin{array}{l}\text { 富 } \\
\text { 苛 }\end{array}$ & 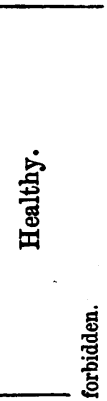 \\
\hline 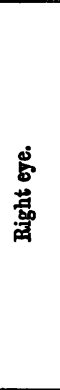 & $\begin{array}{l}\text { 害 } \\
\text { 嵒 }\end{array}$ & $\begin{array}{l}\text { 空 } \\
\text { 芯 } \\
\text { 恶 }\end{array}$ & 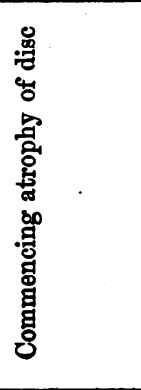 & 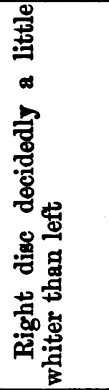 & 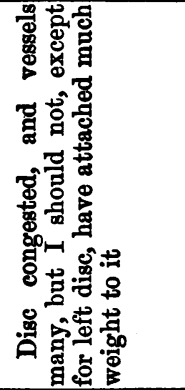 & 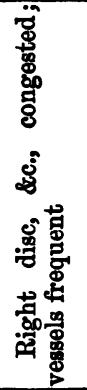 & 兽 \\
\hline 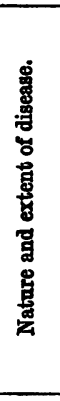 & 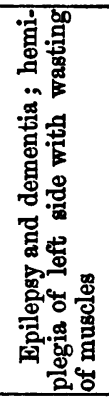 & 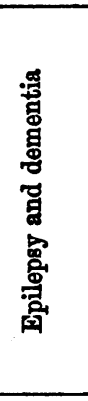 & 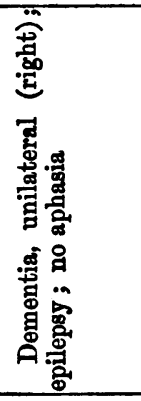 & 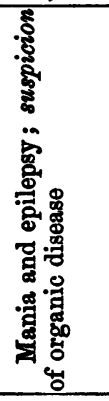 & 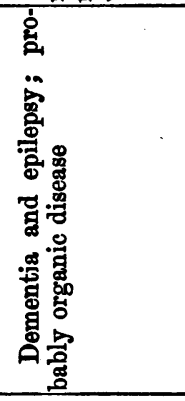 & 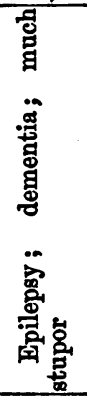 & 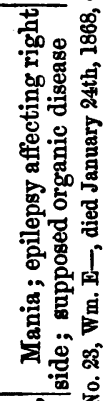 \\
\hline \multirow[t]{2}{*}{ 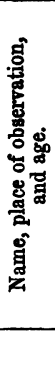 } & 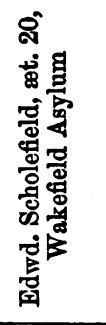 & 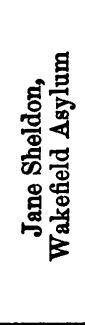 & 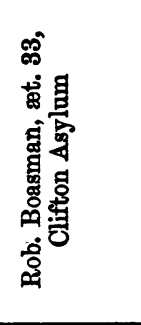 & 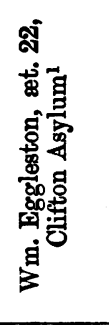 & 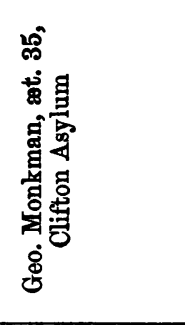 & 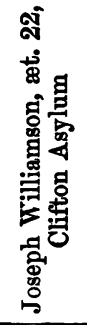 & 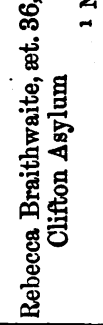 \\
\hline & ని & $\vec{d}$ & สิ & ศึ & $\boldsymbol{N}$ & ลี & คै \\
\hline
\end{tabular}


AS SEEN IN THE INSANe.

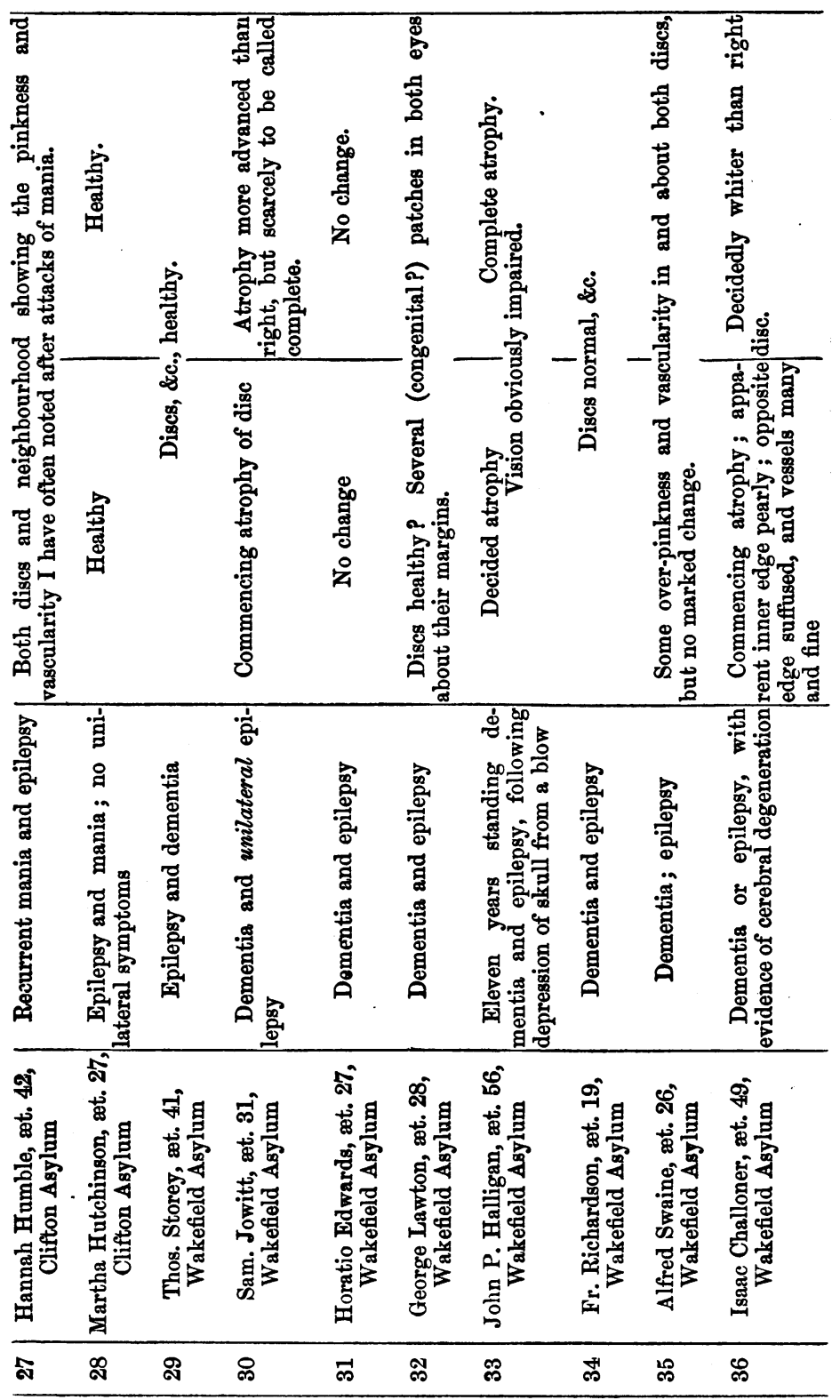




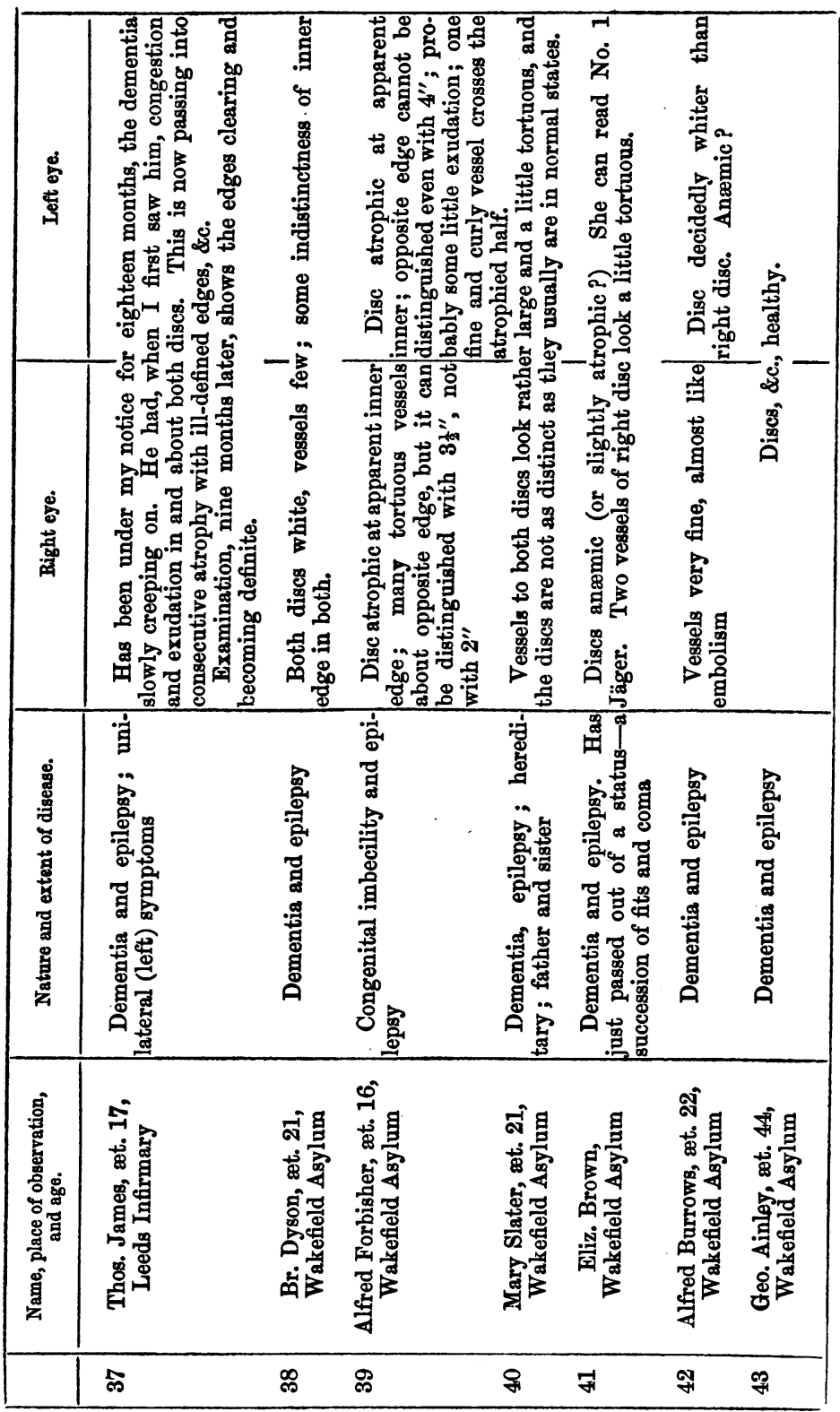


My last table is one of idiocy.

I examined some idiots because I had formed a suspicion from the few cases which had occurred in my own practice, that atrophy of the optic nerves was not uncommon in idiocy. It will be seen that of 12 cases $I$ note very decided atrophy of the discs in 5, and advancing disease in 1, while 2 may be called doubtful. Whether this be due to encephalic inflammations in childhood, or to whatever causes it may be, I leave to future observers to say. 


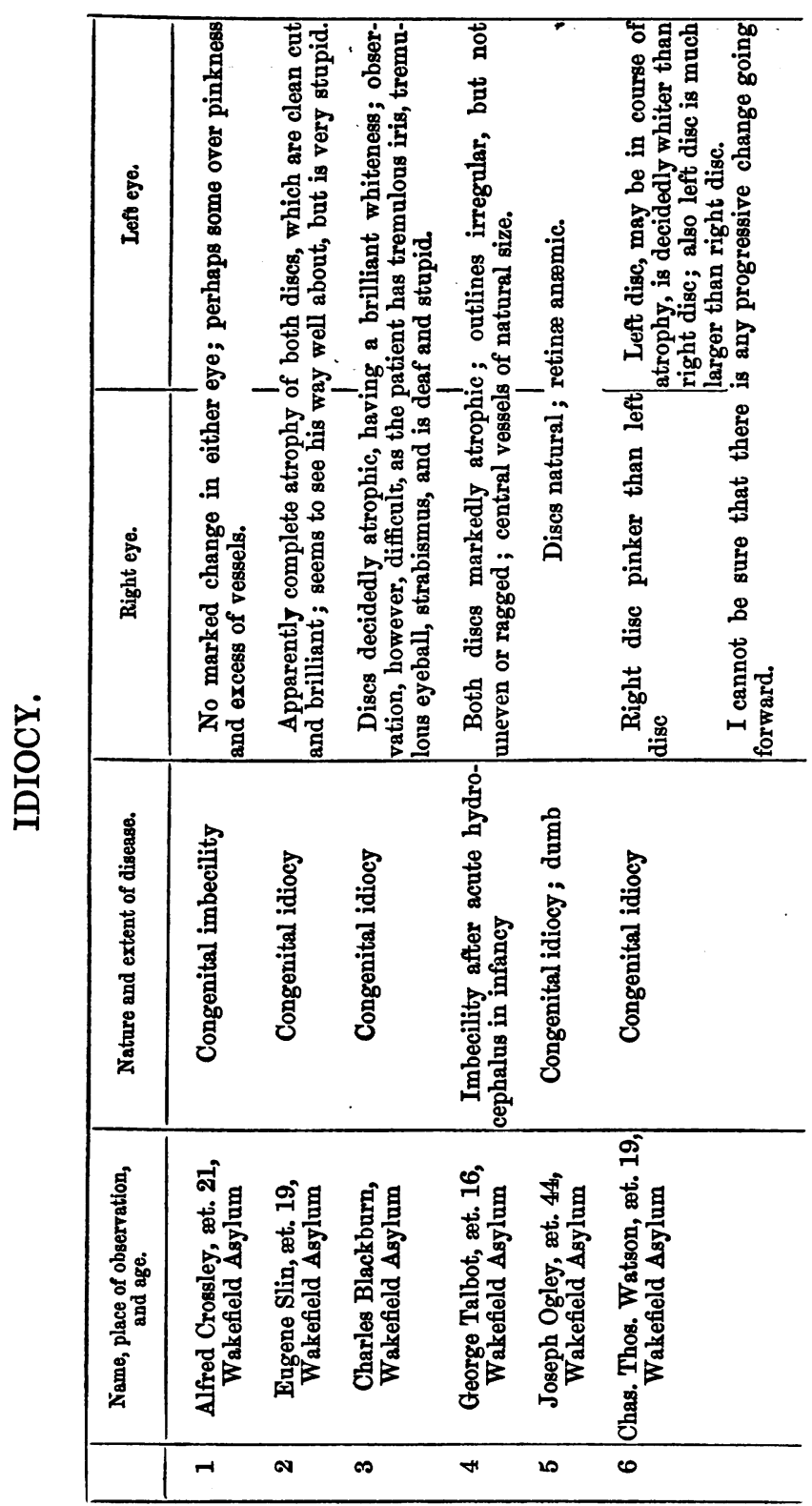




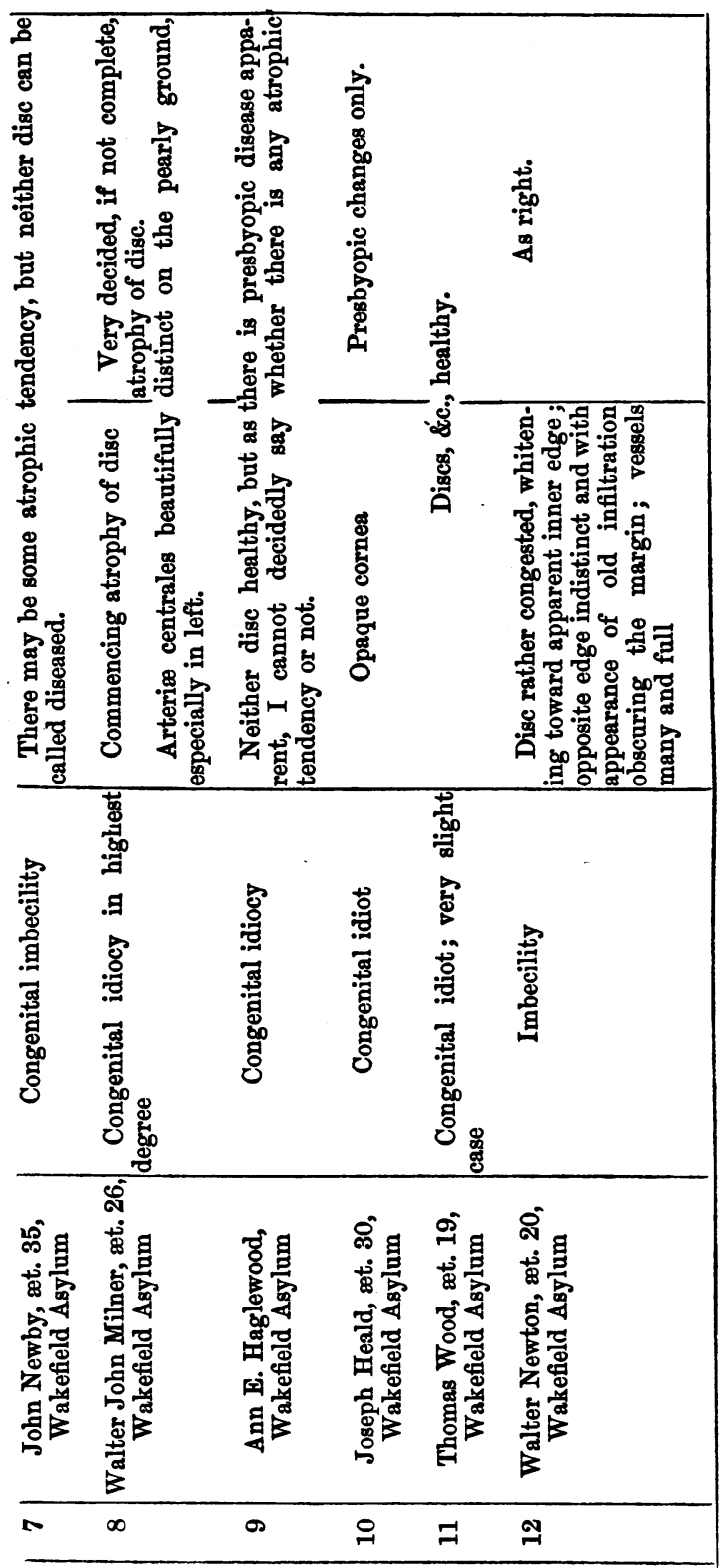


Such are the few remarks which I venture to make upon my observations. The main interest of my communication must still lie in the schedules themselves. To enter upon a study of these in detail would be to detain the Society very unreasonably. I point out the main inferences only, namely, that in old or severe organic disease of the brain and its membranes, whether degenerative, hæmorrhagic, meningitic, or due to tumours, obvious changes in the eye are to be seen in a very large proportion.

That in so-called functional diseases, however profound, such changes are to be found only in a very small proportion.

That atrophy of the disc is perhaps a constant symptom of general paralysis, a fact of the highest pathological importance.

That in functional mania and functional epilepsy, but especially in the former, the variations of vascular tension in the retina and disc may have great interest for the observer.

Finally, I hope I have shown that the account of a cerebral disease cannot be complete if without any record of ophthalmic observations. 